ARTÍCULO

\title{
POESÍA Y POLÍTICA EN EL MÉXICO REPUBLICANO: UNA LECTURA DE IGNACIO RAMÍREZ Y DON SIMPLICIO, 1845-1847*
}

\author{
POETRY AND POLITICS IN REPUBLICAN MEXICO: A READING \\ OF IGNACIO RAMÍREZ IN DON SIMPLICIO, 1845-1847
}

\author{
Pablo Piccato \\ Columbia University \\ pp143@columbia.edu
}

\section{Resumen}

Este artículo examina las ideas de Ignacio Ramírez y sus contemporáneos sobre los usos políticos de la poesía. Se concentra en el periodo en el que Ignacio Ramírez y Guillermo Prieto escribieron el periódico satírico Don Simplicio, opositor al gobierno de Mariano Paredes y Arrillaga y al proyecto monarquista. A pesar de la inminencia de la guerra contra los Estados Unidos, Ramírez hizo una crítica del nacionalismo y de la poesía existente. Su objetivo era sentar las bases para un lenguaje público renovado y democrático en el cual la poesía desempeñaría un lugar importante.

Palabras clave: esfera pública, poesía, Ignacio Ramírez, literatura.

\begin{abstract}
This article examines the ideas of Ignacio Ramírez and his fellow contemporaries regarding the political use of poetry. It focuses on the time-period in which Ramírez and Guillermo Prieto wrote the satyrical newspaper Don Simplicio, in opposition to the government of Mariano Paredes y Arrillaga and the monarchist project. Despite the imminence of the MexicoUnited States war, Ramírez criticized both nationalism and the poetry of his own epoch. His aim was to establish the foundations for a renewed and democratic public language in which poetry would play a very important role.
\end{abstract}

Keywords: public sphere, poetry, Ignacio Ramírez, literature, republicanism.

Información del artículo

Recibido: 4 de noviembre de 2019.

Aceptado: 21 de febrero de 2020.

DOI: $10.22201 /$ iih.24485004e.2019.58.71832

* La versión inicial de este artículo fue presentada en el Ciclo de conferencias: "Diálogos del pasado, reflexiones para hoy”, en San Miguel Allende, 20 de junio, 2018. Gracias a Cristina Solís y al Comité organizador por el impulso. Gracias también a Adela Pineda y Saraí García y a los participantes en el encuentro "Mexican Literature, Culture, and Film across Borders: Translation, Migration and Frontiers", realizado en Boston University, 26 de octubre de 2018, a Robert Karl y los colegas de PLAS en Princeton, a los participantes en el Columbia Workshop of Latin American History, a los comentarios de Viviane Mahieux y Carlos Illades, a los consejos de Miguel Ángel Castro y a las indicaciones de dos evaluadores anónimos. 
Mientras Estados Unidos invadía México y el país se sumía en su crisis política más profunda hasta entonces, Ignacio Ramírez se ocupaba de reflexionar sobre la poesía. Mientras sus contemporáneos encomendaban la supervivencia de la nación a Dios y a los generales, Ramírez se burlaba de la religión y el patriotismo. Mientras otros defendían la retórica, la moral y las leyes, él sugería poner la ficción al servicio del placer que daba reírse de la estupidez nacional. Pero Ramírez no hacía nada de esto por contreras. En sus primeros escritos, en el periódico satírico Don Simplicio, planteó una crítica radical al lenguaje usado en la política y una propuesta original sobre el papel de la poesía en la vida pública.

Ramírez pensaba, como muchos de sus contemporáneos, que la literatura tenía una función esencial en la vida social y política. A diferencia de ellos, sin embargo, Ramírez proponía que para cumplir esa función había que utilizar a la sátira para criticar a la poesía existente (a la que declaraba "en bancarrota") y al discurso político. Eventualmente, pensaba Ramírez, la poesía se convertiría en un medio de comunicación dirigido a un público escéptico e inteligente, un arte definido por la práctica más que por la tradición o las influencias extranjeras. Ramírez desarrollaría en forma teórica estas ideas en clases de literatura en los años siguientes, y en las que propuso estudiar al lenguaje como parte de la vida social. Pero fue en los versos y las reflexiones sobre la literatura que Ramírez escribió para Don Simplicio donde vemos su propuesta práctica para hacer de la poesía parte central de un nuevo lenguaje, como arma de la inteligencia que desafiaría la retórica y las ideologías que en esos años comenzaban a cristalizar en partidos. Este lenguaje podría movilizar humores y sentimientos, es decir, conectar mejor que el discurso político existente al sujeto con la política, y con ello lograr una sociedad más justa. ${ }^{1}$

En la literatura mexicana del siglo XIX confluyeron distintas ideas sobre la tradición y la originalidad, y sobre las posibilidades del lenguaje usado en el ámbito público. Entre los varios productos culturales disponibles en las primeras décadas de vida independiente, la poesía se destacaba por

${ }^{1}$ José Joaquín Blanco, en cambio, recomienda una lectura metafórica de Ramírez en José Joaquín Blanco, "Destellos de El Nigromante: retratos con paisaje”, Nexos: Sociedad, Ciencia, Literatura, v. 27, n. 326, febrero de 2005. Disponible en https://www.nexos.com.mx/?p=11413. Estoy de acuerdo con Ray-Alexander en la importancia de considerar la teoría literaria de Ramírez para entender su contribución política. (Christopher Mark RayAlexander, Blood, Sweat, and Tears. Literary Creation and National Sentiment in 19th Century Mexico, tesis de doctorado, The Johns Hopkins University, 2016, p. 242). 
circular libre de las limitaciones asociadas a una subordinación colonial o a la desventaja material que afectaba el resto de la economía: era fácil de producir (como forma de escritura, siguiendo ciertos modelos, y como objeto material, impresa en diarios y pasquines) y de disfrutar (sobre todo oralmente, en distintas situaciones sociales como tertulias, fiestas patrias o funerales). El verso aparecía muy cercano al periodismo durante estas décadas, en una asociación que hacía de los poetas voces prominentes en los debates públicos.

Este artículo no intenta simplemente leer los versos de Ramírez como vehículos para difundir opiniones. En las páginas de Don Simplicio, la poesía y la poética fueron los instrumentos más importantes en una crítica radical al lenguaje político de la primera mitad del siglo xix. Para sacarle provecho a estos versos hace falta leerlos desde un punto de vista práctico, como parte de una interacción entre autores y lectores en la esfera pública, más que desde una perspectiva puramente literaria o formal. En aquel ámbito, la poesía era parte central del lenguaje que permitía a diversos actores discutir racionalmente, es decir, sin usar la fuerza y sobre la premisa de que era posible llegar a un acuerdo. ${ }^{2}$ Sin embargo, ese lenguaje no era transparente, un mero vehículo para presentar ideas, sino que las transformaba al hacerlas parte de un intercambio dialógico de consecuencias prácticas. Por esa razón, para entender la política hay que entender la poética que respaldaba esa concepción de la poesía como forma de comunicación. Según la teoría que entonces ofreció Ramírez, no era suficiente con darle rima a las ideologías y mantener su significado literal: eran necesarias la ironía y la ficción, que a su vez transformaban la manera en que se entendía la realidad. Junto con el teatro, la poesía era en ese momento la forma dominante de la ficción literaria. Lo que distinguía a la poesía era su capacidad de llevar el lenguaje más allá de sus usos cotidianos y del significado unívoco de las palabras. Por lo tanto, examinar la interacción entre la forma y el significado en el poema puede ayudarnos a entender mejor los límites del discurso político. Para ello debemos recordar que la poesía refiere a un contexto

${ }^{2}$ A diferencia de la noción de opinión pública, la esfera pública es un concepto del siglo xx que describe un espacio virtual y abierto de discusión en el que la sociedad civil puede debatir temas de interés común sobre la base de un lenguaje compartido y racional, Pablo Piccato, La tiranía de la opinión. El honor en la construcción de la esfera pública en México, traducción de Lucía Rayas, México, El Colegio de Michoacán/Instituto de Investigaciones Dr. José María Luis Mora, 2015. 
pero no depende de él. Como propone Eagleton, la poesía es una forma de ficción "in the service of moral truth". ${ }^{3}$

Esta lectura requiere un esfuerzo adicional cuando se ocupa de la sátira, el género que Ramírez usó exclusivamente en este periodo. Los lectores juzgaban a la sátira de acuerdo con sucesos contemporáneos, y luego la olvidaban con facilidad. Los críticos también la tienden a olvidar, tal vez por considerarla más alejada de la idea normativa del arte puro que se iría imponiendo entre románticos y modernistas. Es más complicado descifrar la sátira que la poesía lírica, porque la primera remite a una esfera pública que es fundamentalmente oral, personal, irónica y elusiva, mientras que la lírica se puede entender en términos de sentimientos subjetivos de acuerdo con un repertorio formal y tropos establecidos. Es más fácil suponer, desde la distancia del presente, qué palabras podían evocar emociones patrióticas o eróticas. Definir qué contenía una burla (en forma de ironías, alusiones, comparaciones) era difícil incluso en los juicios por delitos de prensa, donde la sátira era objeto de análisis más frecuentemente que en la crítica literaria. Si nos guiamos por los resultados de los jurados de imprenta que actuaron durante el siglo xıx en México, era casi imposible decidir objetivamente qué escritos contenían un significado ofensivo. ${ }^{4}$

La poética de Ramírez en Don Simplicio era un proyecto literario y político que no podemos reducir a las predecibles dicotomías ideológicas o estilísticas (liberales y conservadores, republicanos y monarquistas, románticos y clasicistas). Se trataba de un proyecto literario porque, como

3 Terry Eagleton, How to Read a Poem, Malden (Massachussets), Blackwell, 2007, p. 35. Los poemas tienen contenido moral "not because they launch stringent judgements according to some code, but because they deal in human values, meanings and purposes", p. 29. Sigo a Eagleton en su definición general de poesía: "poetry can be regarded as the truth of language in general, in that it reveals how verbal form shapes meaning”, p. 15. La poesía, como propone Ángel Rama, "es un sistema productivo privilegiado [...] en que la ideología cumple función preponderante”. Ángel Rama, "Indagación de la ideología en la poesía (Los dípticos seriados de Versos sencillos)”, en Ángel Rama, La crítica de la cultura en América Latina, selección y prólogos de Saúl Sosnowski y Tomás Eloy Martínez, Caracas, Biblioteca Ayacucho, 1985, p. 132.

${ }^{4}$ Monsiváis señalaba la dificultad de leer a Ramírez y sus contemporáneos porque exigir "la traducción de su retórica, del sistema de modos de decir, de elocuencias cuya intensidad sólo es apreciada en una época específica, de señales culturales que cobran cabal expresividad por unos años, ni antes ni después". Carlos Monsiváis, "La expresión radical de Ignacio Ramírez", en David R. Maciel (ed.), Obras completas de Ignacio Ramírez "El Nigromante”, México, Centro de Investigación Científica Jorge L. Tamayo, 1984, v. 3, p. v-Xxx, p. XXI. 
lo han señalado otros estudiosos, intentaba separar la retórica de la literatura, y porque partía de la premisa de que la sátira era la manera más efectiva de discutir la situación actual del país; pero también era un proyecto político por su énfasis en la importancia práctica del lenguaje y la comunicación ante la anomia en que parecía sumirse el país. ${ }^{5}$ Tampoco es fácil situar históricamente este momento donde todo estaba en juego, desde la constitución del país hasta su propia extensión territorial. Las etiquetas ideológicas usuales no son muy útiles en este contexto porque los sistemas constitucionales aún carecían de suficiente firmeza para ser juzgados por sus efectos, y los portavoces de las ideologías frecuentemente cambiaban de posición. ${ }^{6}$ Varios trabajos históricos recientes concuerdan en que la década de los cuarenta significó una expansión en los temas y las voces en el debate político. ${ }^{7}$ La dirección de que tomarían la república

${ }^{5}$ Christopher Domínguez Michael, La innovación retrógrada. Literatura mexicana, 18051863, México, El Colegio de México, 2016, p. 527. El mejor análisis de ese discurso es Leonardo Martínez Carrizales, "Ignacio Ramírez, teórico de la literatura”, en Ignacio Ramírez, La palabra de la Reforma en la república de las letras. Una antología general, México, Universidad Nacional Autónoma de México, 2009. Estos esquemas no sirven para entender la perspectiva crítica de Ramírez hacia la literatura. Sobre el programa sociopolítico de Ramírez en Don Simplicio, en David Maciel, “Don Simplicio y El “Nigromante”, Relaciones, v. 2, n. 8, 1981.

${ }^{6}$ Miguel Ángel Castro, "Ignacio Ramírez, lecturas pendientes”, en Ignacio Ramírez, La palabra de la Reforma en la república de las letras. Una antología general, México, Universidad Nacional Autónoma de México, 2009. En las interpretaciones más recientes de la historia intelectual, estas clasificaciones ideológicas se han convertido en referencias dominantes que han perdido de vista la dimensión práctica del lenguaje que estos actores ponían en juego. Así, los intelectuales más destacados del periodo se convierten en voceros que encarnan, con mayor o menor corrección, ideas que reciben de circuitos atlánticos. Ejemplos recientes de esta historiografía muestran una mayor complejidad de la que describo aquí, pero mantienen los mismos ejes analíticos. Rafael Rojas y José Antonio Aguilar, El republicanismo en Hispanoamérica. Ensayos de historia intelectual y política, México, Centro de Investigación y Docencia Económicas/Fondo de Cultura Económica, 2002; Rafael Rojas, La escritura de la independencia. El surgimiento de la opinión pública en México, México, Taurus/Centro de Investigación y Docencia Económicas, 2003. Un ejemplo clásico es Jesús Reyes Heroles, El liberalismo mexicano, México, Universidad Nacional Autónoma de México, 1957. Un modelo en Charles A. Hale, Mexican Liberalism in the Age of Mora, New Haven, Yale University Press, 1968. Una crítica muy útil en Ariel de la Fuente, "Los comentaristas del Facundo y sus prejuicios. Respuesta a Adriana Amante y a Elías Palti”, Boletín del Instituto de Historia Argentina y Americana "Dr. Emilio Ravignani", n. 44, 2016.

7 Elías Palti, La política del disenso. La "polémica en torno al monarquismo" (México, 18481850)... y las aporías del liberalismo, México, Fondo de Cultura Económica, 1998; Pedro Santoni, Mexicans at Arms. Puro Federalists and the Politics of War, 1845-1848, Fort Worth, Texas Christian University Press, 1996. 
las décadas siguientes era algo que nadie, ni siquiera los productores de ficción, podía imaginar.

\section{Ramírez y Don Simplicio}

Ignacio Ramírez (1818-1879) se había hecho conocer en los círculos intelectuales de la ciudad de México por negar la existencia de dios y por haber pasado ocho años, después de graduarse de abogado, leyendo de todo en las bibliotecas de la catedral y del Colegio de San Gregorio. Ramírez llegaría a tener en las décadas siguientes una influencia considerable en la lucha por la secularización del Estado y el establecimiento del liberalismo en México. A mediados de los cuarenta, sin embargo, su principal objetivo político era burlarse de las hipocresías católicas y nacionalistas de sus contemporáneos y combatir el monarquismo y el liberalismo moderado. ${ }^{8}$ En el proyecto lo acompañaban otros escritores que adquirirían el mismo prestigio dentro de movimiento liberal en las décadas posteriores, como Guillermo Prieto y Manuel Payno - aunque éste no como redactor-. El momento de Don Simplicio es singular porque Ramírez aprovechó entonces una libertad (diríamos que una irresponsabilidad) que se diluiría tras su incorporación plena a la lucha política y militar contra invasores, conservadores y monarquistas. Ramírez eventualmente asumió obligaciones como maestro, legislador y juez, pero continuó siendo una piedra en el zapato para sus correligionarios. Nunca intentó ser un caudillo; fue ministro de la Suprema Corte, pero nunca tuvo mucho capital político, y se las arregló para perder el favor de tres presidentes consecutivos (Juárez, Lerdo y Díaz) y jamás llegar a tener dinero. Antes de convertirse en un prócer de la generación de la Reforma, sin embargo, Ramírez ofreció la crítica más radical, previa a la de los modernistas, a la relación entre poesía, poetas y vida pública.

Don Simplicio fue de los primeros periódicos mexicanos en el que el verso no era un adorno, sino un instrumento para presentar argumentos y

8 Tratamientos biográficos de Ramírez incluyen a David Maciel, Ignacio Ramírez, ideólogo del liberalismo social en México, México, Universidad Nacional Autónoma de México, 1980; Ignacio Manuel Altamirano, "Biografía de Ignacio Ramírez”, en Ignacio Ramírez, Obras de Ignacio Ramírez, edición de Ignacio Manuel Altamirano, México, Oficina Tip. de la Secretaría de Fomento, 1889; Emilio Arellano, Ignacio Ramírez, El Nigromante. Memorias prohibidas, México, Planeta, 2009. Los trabajos sobre la poesía de Ramírez no se han detenido mucho en su sátira y han hecho énfasis en su poesía amorosa tardía. 
entablar combates políticos. ${ }^{9}$ En su primer número, de diciembre de 1845 , el 48 por ciento del espacio de sus ocho planas estaba en verso. En los números siguientes, que eran de cuatro páginas, el porcentaje andaba por el 20 por ciento. Los poemas podían venir en la primera página, casi siempre había al menos uno en la página dos, y aparecían en todas las demás, sin estar confinadas a una sección en particular. También había versos intercalados en los diálogos, editoriales y ensayos que comprendían el resto del texto.

El periódico apareció en un momento difícil para la república. Hacia mediados de los cuarenta, la clase política mexicana no estaba de acuerdo con nada salvo con la inminencia de un enfrentamiento contra los Estados Unidos tras su absorción de Texas. Los liberales más radicales, algunos de los cuales habían encabezado una fallida revolución en 1840, proponían el regreso a la constitución federalista de 1824 y la convocatoria de milicias cívicas para resistir a los Estados Unidos o incluso recuperar Texas. Los liberales moderados y los conservadores, algunos de ellos inclinados al monarquismo, temían que esa movilización alebrestara a la chusma y debilitara al Estado. A fines de 1845, mientras el gobierno de José Joaquín de Herrera trataba de negociar con Estados Unidos para evitar una invasión, varios estados de la república todavía se negaban a comprometer sus recursos para la defensa nacional. En diciembre, una rebelión apoyada por tropas que debían ir a combatir a los invasores derrocó a Herrera y llevó a la presidencia al general Mariano Paredes y Arrillaga. Aparte de su ambición personal, Paredes y Arrillaga defendía un programa basado en limitar el

${ }^{9}$ Para el contexto, el proyecto político, la recepción y el uso de la sátira, véase la excelente tesis de Alejandra Sánchez Archundia, Desde la Asnópolis. Narraciones de la nación 'Desde Abajo': Don Simplicio (1845-1847), tesis de licenciatura en Historia, México, Universidad Nacional Autónoma de México, 2011. Agradezco a uno de los evaluadores anónimos de este artículo por la referencia. En el uso del verso, Don Simplicio parece haberse adelantado a otros periódicos satíricos españoles conocidos en México. Una referencia a Fray Gerundio en Don Simplicio, t. 2, n. 33, 22 de abril de 1846, p. 1. Se trataba de un periódico satírico pero sin verso publicado entre 1837 y 1842. Mónica Fuertes-Arboix, La sátira política en Fray Gerundio (1837-1842) de Modesto Lafuente, tesis de doctorado de The Ohio State University, 2006. Poesía satírica en los periódicos en Inglaterra durante estos años en Steven E. Jones, "Nineteenth-Century Satiric Poetry", en Rubén Quintero (ed.), A Companion to Satire: Ancient and Modern, Maiden (Massachussets), Blackwell Publishing, 2007. El teatro fue otro terreno donde la sátira expandía el vocabulario político, y al que los redactores de Don Simplicio también hacían alusión. Lance R. Ingwersen, Mexico City in the Age of Theater, 1830-1901, tesis de doctorado, Universidad de Vanderbilt, 2017. 


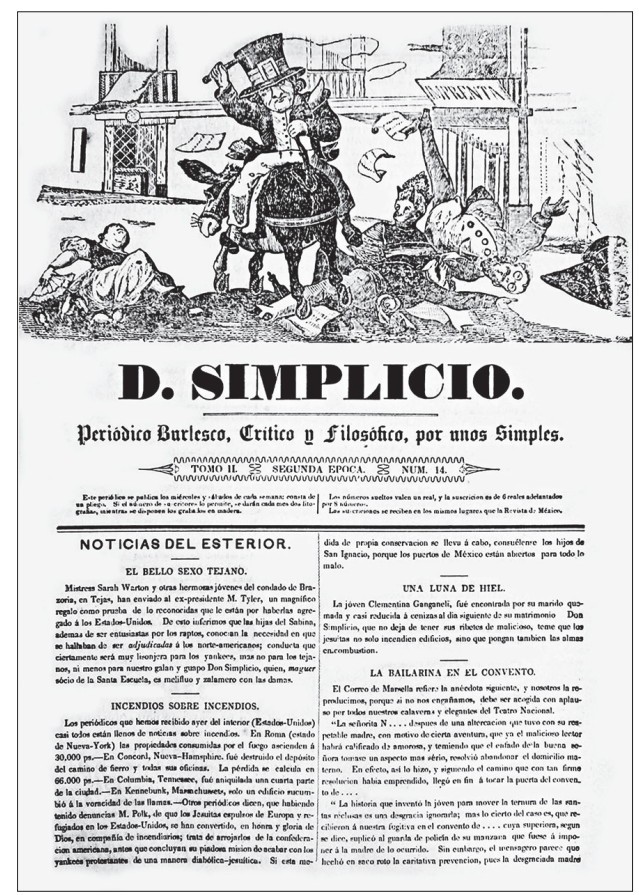

Figura 1

Fuente: Don Simplicio, agosto de 1845

derecho al sufragio y la representación, y subrepticiamente encaminado a establecer una monarquía. ${ }^{10}$

Don Simplicio era publicado bisemanalmente. La mitad de la primera página era un grabado en el que Don Simplicio, andando en burro al revés, castigaba a una mujer de sociedad, un cura, un militar y un licenciado (figura 1). Además de Ramírez, eran miembros del equipo Guillermo Prieto

${ }^{10}$ Santoni, Mexicans at Arms..., p. 30, 33-37, 39, 55; Josefina Zoraida Vázquez, "Search of Power: The Pronunciamientos of General Mariano Paredes y Arrillaga", en Will Fowler (ed.), Malcontents, Rebels, and Pronunciados: The Politics of Insurrection in Nineteenth-Century Mexico, Lincoln, University of Nebraska Press, 2012. El primer texto histórico sobre la guerra, en el que participaron Ramírez, Payno y Prieto, confirma la incertidumbre. Guillermo Prieto y varios, Apuntes para la historia de la guerra entre México y los Estados Unidos [edición facsimilar de la de 1848], México, Siglo XXI Editores, 1970, p. 222-234. Muchos seguidores de Paredes y Arrillaga no creían que la monarquía estuviera entre sus planes. Véase, por ejemplo, Ignacio de Mora y Villamil, Carta a Mariano Paredes y Arrillaga, Veracruz, 30 de marzo de 1846, Benson Latin American Collection, University of Texas at Austin, Mariano Paredes y Arrillaga Papers (en adelante, BLAC, MPAP), exp. 144 G, doc. 674. 
y Vicente Segura Argüelles. Vicente García Torres y Juan de la Granja fueron impresores. No es claro quién pagaba por su producción. Cada ejemplar costaba un real e incluía pocos anuncios comerciales. Su propósito era polémico antes que electoral, pues no apoyaba a ningún partido o candidato. Desde sus primeros números se dedicó a atacar el proyecto conservador y monarquista que divulgaba otra publicación, El Tiempo, aparecida unos días después que Don Simplicio, en enero de 1846, con el apoyo disimulado del general Mariano Paredes y Arrillaga, a quien Don Simplicio criticaba de manera indirecta para evitar la persecución. Era obvio que El Tiempo tenía algún tipo de apoyo económico, pues era publicado todos los días de la semana, incluso los domingos, con cuatro páginas en formato grande, cuidadosamente impresas pero con escasas ilustraciones. La solemnidad del diseño de El Tiempo evocaba la importancia que sus editores le atribuían a la empresa: "la gran cuestión política de México, es la de ser o no ser: o vivirá bajo un gobierno firme y que la haga respetable, o desaparecerá para siempre del catálogo de las naciones [...]. Para México ha llegado un momento solemne, una crisis suprema, en la que va a quedar decidida su suerte para siempre". La salvación, para ellos, estaba en "el caudillo" de la última revolución (Paredes y Arrillaga). ${ }^{11}$

Había una curiosa asimetría en el combate que buscaba Don Simplicio: mientras El Tiempo, cuyo adversario manifiesto del lado liberal era El Monitor Republicano, se caracterizaba por la elevación del estilo, la corrección en la escritura y una cuidadosa retórica, Don Simplicio respondía "con sarcasmo y ridículo”, sin preocuparse por las formas. Don Simplicio de paso también se mofaba de El Monitor Republicano, cuya timidez moderada le impedían elogiar o vituperar al gobierno. ${ }^{12}$ Mientras Don Simplicio hacía frecuentes referencias a El Tiempo, éste ignoraba casi completamente a su rival. Aunque éste tenía una sección diaria con noticias y comentarios de otros periódicos mexicanos, sólo encontré una referencia a Don Simplicio, al que definía como "periódico burlesco" que injustamente acusaba al ejér-

11 "Parte política”, El Tiempo, t. 1, n. 8, 31 de enero de 1846, p. 1. Sánchez Archundia, Desde la Asnópolis. Narraciones de la nación..., p. 53, especula que el minero Domingo Revilla puede haber apoyado a la publicación de Don Simplicio.

12 "Al Monitor", Don Simplicio, t. 2, n. 16, 21 de febrero de 1846, p. 4. Guillermo Prieto, Obras completas. Volumen 1. Memorias de mis tiempos, edición de Boris Rosen Jelómer, México, Consejo Nacional para la Cultura y las Artes, 2005, p. 381; Altamirano, "Biografía de Ignacio Ramírez". Un panorama del periodismo en ese momento en EE, "Revista política y literaria”, 261-2, en Revista Científica y Literaria de Méjico publicada por los antiguos redactores del Museo Mejicano, México, Imp. Calle de la Palma, 1845, v. 2. 
cito por las desgracias de la patria. ${ }^{13}$ Por su parte, Don Simplicio no reconocía la consistencia ideológica y la competencia literaria como credenciales de superioridad. Según Prieto, los responsables de El Tiempo, que incluían al político conservador y correctísimo estilista Lucas Alamán y al ministro de España Salvador Bermúdez de Castro, un "poeta notable", defendían doctrinas "retrógradas expuestas con las galas del bien decir, y con esa flexibilidad hipócrita que pone lo más santo de parapeto para conseguir los más indignos fines". La realidad ofrecía la mejor contradicción a la retórica. Prieto, con el seudónimo de Zancadilla, publicaba en Don Simplicio poemas y artículos que ridiculizaban una situación política en la que reinaban las máscaras y la estridencia: "esta es la patria del carnaval continuo", afirmaba. ${ }^{14}$

Paredes y Arrillaga retiró su apoyo a El Tiempo, cerrado en febrero de ese 1846 , y censuró a otros periódicos, incluyendo Don Simplicio. ${ }^{15}$ En marzo, el gobierno prohibió la discusión sobre formas de gobierno en los periódicos. En abril, Don Simplicio anunció el cese de su publicación por culpa de la persecución y salió con sus columnas en blanco ${ }^{16}$ (figura 2). Una última época de publicación inició a mediados de 1846, después de la caída de Paredes y Arrillaga y cuando los redactores recuperaron su libertad, para terminar definitivamente en abril de 1847. Ramírez y los otros editores sufrieron prisión y la guerra los obligó a tomar caminos separados. ${ }^{17} \mathrm{El} \mathrm{de-}$ bate sobre el monarquismo se interrumpió porque la invasión estadounidense iniciada en mayo de 1846 alcanzó la ciudad de México en agosto de

13 "Prensa nacional", El Tiempo, t. 1, n. 23, 16 de febrero de 1846, p. 3. La referencia incluía la transcripción de tres párrafos de un artículo, "Oratoria. Primer rebuzno de Don Simplicio. Al Tiempo", Don Simplicio, t. 2, n. 14, 14 de febrero de 1846, p. 3. El editorial era una declaración contra el monarquismo y contra el republicanismo hasta entonces existente en el país, basado en "guardias pretorianas". No encontré las referencias polémicas directas de Alamán a Ramírez que señala RayAlexander, Blood, Sweat, and Tears..., p. 5.

14 Zancadilla, "Bailes de Máscara", Don Simplicio, t. 2, n. 16, 21 de febrero de 1846, p. 1-2. Prieto también escribía en El Monitor. Prieto, Obras completas..., 1, p. 379. Prieto ya había ofrecido su crítica al lenguaje culterano en los debates políticos. Véase "Carta a Juan Soplillo. (Contestación a un artículo de La Esperanza del viernes 1 del corriente.)”, p. 13-21; publicado en El Siglo Diez y Nueve, 6 de julio de 1842, p. 3-4, en Guillermo Prieto, Obras completas. XIV. Poesía satírica. Poesía religiosa, Boris edición de Rosen Jélomer, México, Consejo Nacional para la Cultura y las Artes, 1995, p. 14-19.

15 “El Tiempo", Don Simplicio, t. 2, n. 16, 21 de febrero de 1846, p. 4.

${ }^{16}$ Don Simplicio, t. 2, n. 34, 23 de abril de 1846; Miguel Soto Estrada, La conspiración monárquica en México, 1845-1846, México, Offset, 1988, p. 156, 178.

${ }^{17}$ Maciel, Ignacio Ramírez, ideólogo..., p. 130; Ignacio Manuel Altamirano, "Biografía de Ignacio Ramírez”, en Ramírez, Obras de Ignacio Ramírez, p. 27; Arellano, Ignacio Ramírez, El Nigromante..., p. 50-51. 


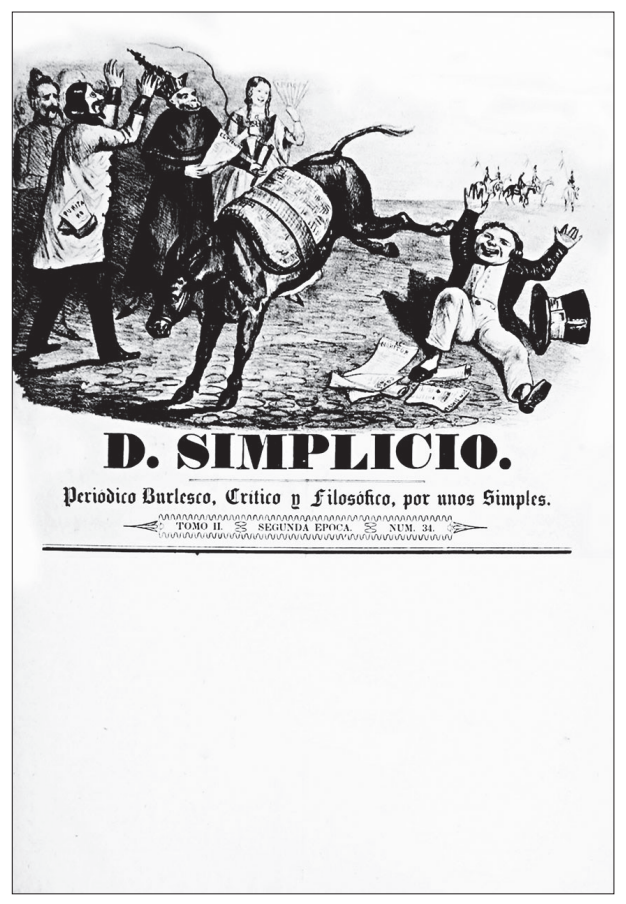

Figura 2. Número de Don Simplicio con páginas en blanco Fuente: Don Simplicio, t. II, 2a. época, n. 34, 23 de abril de 1846

1847, poniendo en perspectiva las enemistades ideológicas. En su huida de los gringos, por ejemplo, Prieto se refugió en la casa de Alamán. ${ }^{18}$

Según Ignacio Manuel Altamirano, discípulo y primer biógrafo de Ramírez, la idea en Don Simplicio también era atacar a los liberales moderados que creían que la constitución de 1824 iba a ser la solución de todos los problemas nacionales. ${ }^{19}$ Lo cierto es que la coyuntura de la guerra expandió los objetivos del periódico de una manera inesperada, convirtiendo a la sátira en una forma de atacar el nacionalismo que proclamaban todos los grupos políticos. Desde su pesimismo, Don Simplicio se burló del

${ }^{18}$ Los dos rivales tuvieron tiempo para conversar mucho sobre literatura pero, lamentaría Prieto años después, no el suficiente como para reconciliar sus diferencias políticas. Prieto, Obras completas..., v. 1, p. 409-410; Palti, La política del disenso..., p. 19. En 1848, ya retirados los invasores, El Universal tomó el relevo monarquista y durante los años siguientes la disputa continuó en otros terrenos, tanto intelectuales como militares, hasta cerrarse con la caída de Maximiliano en 1867. Soto Estrada, La conspiración monárquica en México...

19 Altamirano, "Biografía de Ignacio Ramírez”, en Ramírez, Obras de Ignacio Ramírez, p. I-LXXII. 
patriotismo vacío e inefectivo de los generales y políticos mexicanos. Al hacerlo describía sin ambages la anomia que caracterizaba la vida pública nacional. Ramírez escribía en febrero de 1846, por ejemplo, que en México no había instituciones, que las costumbres estaban corrompidas, y que le era difícil imaginar algo mejor para el futuro, salvo cuando se encontraba "inspirado por mi botella". ${ }^{20}$

Aunque los historiadores han caracterizado al proyecto de Don Simplicio como revolucionario, sería especulativo describir un programa político específico en sus páginas. No es fácil, por ejemplo, saber quién era el lector ideal del periódico: ¿las élites educadas que podían entender los chistes cultos de algunos textos? ¿̇o un público más popular y urbano, conocedor de la reputación de los políticos aludidos en esas páginas? Probablemente fueron ambos. ${ }^{21}$ Sus textos sin duda alcanzaban a los niveles más altos del gobierno. El presidente Paredes y Arrillaga y su gabinete leyeron, y no quedaron muy contentos con versos que, según Prieto, tenían "gran boga" entre los lectores. Las consecuencias eran previsibles, pero la censura parecía validar la importancia del proyecto. Prieto recordaría años más tarde que las sátiras de Don Simplicio causaron en su contra "amagos de palizas y contrariedades de todo género". ${ }^{22}$ Los redactores, incluyendo a Ramírez, pasaron una temporada en la cárcel. García Torres, que también editaba El Monitor Republicano, fue enviado al exilio. La censura, para ellos, era un esfuerzo inútil que, de alguna manera, confirmaba su visión del estado de cosas, pues

...para un gobierno fiel, son pueriles diversiones conjurar conspiraciones con espadas de papel. ${ }^{23}$

${ }^{20}$ Don Simplicio, t. 2, n. 1, 1 de enero de 1846, p. 4.

${ }^{21}$ Para el problema de públicos y autores de distintas clases en publicaciones satíricas posteriores, véase Robert M. Buffington, A Sentimental Education for the Working Man: The Mexico City Penny Press, 1900-1910, Durham (North Carolina), Duke University Press, 2015. Don Simplicio era leído y mencionado por lectores diversos. Véase Francisco Banuet (?), Carta a Valentín Gómez Farías, Ocotlán, 2 de agosto de 1846, BLAC, Valentín Gómez Farías Collection (en adelante VGFC), fólder 49, doc. 1453; Gobernador Antonio Escobedo, Carta a Mariano Paredes y Arrillaga, Guadalajara, 24 de febrero de 1846, BLAC, MPAP, exp. 144 D, doc. 335. Sobre el carácter dialógico y la participación de un "pueblo" definido ampliamente en Don Simplicio, véase Sánchez Archundia, Desde la Asnópolis..., cap. 2.

22 Prieto, Obras completas, p. 382, 399.

23 “El Tiempo", Don Simplicio, t. 2, n. 16, 21 de febrero de 1846, p. 4. 
Proyecto político

Para leer a Ramírez en este momento es necesario considerar los varios registros de sus escritos. En los años de Don Simplicio el contexto cambiaba tan rápido que sería ocioso reconstruir las referencias inmediatas a la situación política en cada poema. ${ }^{24}$ Ramírez y sus socios concebían a Don Simplicio como una plataforma que iba más allá de las circunstancias cotidianas y se dirigía a cambiar el lenguaje mismo de la vida pública.

Ramírez sabía que enfrentar al gobierno en la arena periodística no iba a provocar un movimiento popular, y tenía una apreciación mesurada de la importancia de Don Simplicio y la prensa en general. Esa modestia le permitía incursionar sin muchas preocupaciones en los campos superpuestos de la literatura y la política. La crisis nacional y su propia carencia de afiliaciones políticas creaban una oportunidad en la que todo era posible desde el punto de vista del contenido y el estilo. Ramírez no era un liberal puro y no ocultó su escepticismo hacia el federalismo, el centralismo o cualquiera de las ideologías en juego en ese momento. ${ }^{25}$ No tenía ninguna fe en el patriotismo como redención de los problemas nacionales, particularmente el profesado por los generales y las masas. Desde el punto de vista de la historia política, clasificar a Ramírez como un liberal más significaría perder muchos matices de su pensamiento. Así lo sugería Justo Sierra, quien definió a Ramírez como un miembro incómodo de esa "guerrilla de la pluma" que rodeaba a Juárez, singular por su "áspero sarcasmo" que "tendía a demolerlo todo". ${ }^{26}$

Los argumentos de Ramírez contra el monarquismo incluían dos ideas que distinguirían su pensamiento en las décadas siguientes. En primer lugar,

${ }^{24}$ Carlos Monsiváis, "La expresión radical de Ignacio Ramírez”, en Boris Rosen y David R. Maciel (eds.), Obras completas de Ignacio Ramírez, "El Nigromante”, México, Centro de Investigación Científica Ing. Jorge L. Tamayo, 1984, v. 3, p. XxI.

${ }^{25}$ La tentación de usar una clave puramente ideológica es grande. Christopher Domínguez Michael, por ejemplo, lo llama anticomunista. Su biógrafo David Maciel lo define como un liberal avanzado por sus preocupaciones socialistas. Domínguez también señala que la escritura de Ramírez buscaba ampliar las posibilidades métricas y léxicas de la poesía, usando la sátira para corregir las costumbres y defender la libertad de imprenta. Christopher Domínguez Michael, La innovación retrógrada. Literatura mexicana, 1805-1863, México, El Colegio de México, 2016, p. 504, 176, 178, 185; Monsiváis, "La expresión radical de Ignacio Ramírez...”, p. xxi; Maciel, Ignacio Ramírez, ideólogo...

${ }^{26}$ Justo Sierra, Juárez: su obra y su tiempo, México, Universidad Nacional Autónoma de México, 1984, v. 3, p. 133. 
se trataba de hacer explícito un aspecto del significado histórico del monarquismo que sus defensores no podían disimular: la monarquía implicaba volver a un sistema colonial que, para Ramírez, había traído el oscurantismo y la explotación. En segundo lugar, Ramírez caracterizaba al monarquismo como un error similar al cometido por otros liberales y conservadores que creían "que un pueblo se puede gobernar muy bien con leyes generales". Esta crítica a las ideologías letradas aparece en varios poemas y en prosas como "Utilidad de El Tiempo". Su adversario monarquista en ese texto, "Don Justo Sólido”, “desdeña los accidentes y sólo ve puras sustancias”. Ramírez señalaba la hipocresía codiciosa de esa operación, pues a los monarquistas "los únicos accidentes que le interesan, son los de su barriga". ${ }^{27}$

Para exhibir los errores de lógica y memoria en el monarquismo, Ramírez evitó el terreno de la teoría política y escogió la poesía y la sátira. Su primer poema, que publicó en el número inaugural de Don Simplicio, "La representación nacional”, ${ }^{28}$ era a la vez una burla y una reflexión política. Escrito en tercetos endecasílabos, una forma usada en el teatro que permitía reproducir varias voces sin demasiada solemnidad, el poema era un diálogo entre "El Nigromante" (seudónimo y personificación literaria de Ramírez) y un "Representante" electo al Congreso por Tampico pero que no conocía el puerto. Las preguntas del Nigromante revelaban la ignorancia del legislador sobre la realidad del país y su pretensión de remediar el problema con silogismos y legislación colonial. La teoría, agregaba el Representante, "la estudiamos en obras inmortales. // Tocqueville, Montesquieu, la Economía / de Ferrier dan saber, fácil, barato”. Nigromante le contestaba que "si [las leyes] han de producir bienes reales, / se aprenden en el pueblo y no en otra obra”. El poema, de 85 estrofas, casi dos planas de las ocho del periódico, daba espacio a diversas perspectivas, burlándose de otros representantes en el Congreso a quienes daba nombres ridículos y sugestivos

${ }^{27}$ Nigromante, "Utilidad del tiempo", Don Simplicio, t. 2, n. 20, 7 de marzo de 1846, p. 2. Véase también "Un pueblo de máquinas”, t. 2, n. 3, 28 de enero de 1846, p. 2. Su escepticismo en Ignacio Ramírez, La palabra de la Reforma en la república de las letras. Una antología general, México, Universidad Nacional Autónoma de México, 2009, p. 199; véase también El Nigromante, “A los viejos”, Don Simplicio, t. 1, n. 1, diciembre de 1845.

${ }^{28}$ Don Simplicio, t. 1, n. 1, diciembre de 1845, p. 6-8. Las Obras completas editadas por Rosen citan el poema incorrectamente: Ramírez, La palabra de la Reforma en la república de las letras..., p. 315. El número 1 del tomo 1 tiene 8 páginas y no está fechado, y parece ser el único correspondiente al tomo I. Contiene referencias a la rebelión de Paredes y Arrillaga del 6 de diciembre. El siguiente número está numerado como tomo II, segunda época, n. 1 y fechado 1 de enero de 1846. 
(Bambolla, don Molesto, Gil, Iscuintli, don Proyectista, don Tripa, Juan) y cuyas veleidades retóricas contrastaba con el sufrimiento del pueblo. En seis estrofas, el Nigromante rechazaba la tradición legal que ligaba la antigüedad griega y romana, el pasado colonial ("siglos tres cebara el fanatismo") para llegar al pasado reciente del centralismo. Afirmaba que "la ley no tiene vida" y, en ocho estrofas, describía los irregulares procedimientos electorales de manera tal que "Risa causa el origen de un congreso". Ante la indignación del Representante, el Nigromante lo acusaba de engañar al pueblo y despreciar al "indio", explotado desde "el latrocinio / de la conquista”. El Representante respondía a esas "blasfemias" contra la propiedad llamándolo "Nigromante del jacobinismo". Contra el vacío de la representación electoral y legislativa, Ramírez prefería la intervención de "la turba". El poema concluía con cuatro estrofas en las que el Nigromante presentaba un proyecto político disfrazado de provocación: el pueblo no puede ser "sacrificado [...] a la ciencia / que forma una nación por alambique", sino que se debe expresar en "tumultuosas juntas" como las del tiempo de Roma, donde emergía un lenguaje nuevo:

En polvorosa plaza el pueblo ufano

a gritos es verdad deliberada,

mas entre áridas voces iba al grano.

La "verdad", en otras palabras, era el debate popular sin los adornos de la retórica. A fines de 1845, la referencia central de "La representación nacional" era un congreso que con Herrera y luego Paredes y Arrillaga en la presidencia aún tenía un papel importante en el orden institucional, pero que carecía del poder y la información suficiente como para influir el curso de los acontecimientos. ${ }^{29}$

"La representación nacional" retrataba los límites del poder legislativo existente, pero también daba dos claves para entender el resto de los es-

${ }^{29}$ Según la crónica de uno de sus miembros, Carlos María de Bustamante, el Congreso en esos días vivía en un estado febril que mezclaba la ignorancia, un sentido del honor quisquilloso, y el impulso de supervisar la acción de un poder ejecutivo que veía como excesivamente ambicioso. Bustamante, Diario histórico de México, 1822-1848... Sobre la coherencia electoral y práctica del legislativo en comparación con la "dismal failure" de las elecciones presidenciales durante esta era, véase Erika J. Pani, "Intervention and Empire: Politics as Usual?”, en Will Fowler (ed.), Malcontents, Rebels, and Pronunciados: The Politics of Insurrection in Nineteenth-Century Mexico, Lincoln, University of Nebraska Press, 2012, p. 237. 
critos de Ramírez en Don Simplicio. Contra la herencia retórica clásica y colonial y las "obras inmortales" del iluminismo racionalista, la nigromancia del autor apelaba a otro pasado heterodoxo. "Nigromante del jacobinismo”, una acusación que Ramírez evocó varias veces con orgullo, invocaba un momento tumultuoso y destructivo de la revolución francesa que a mediados del siglo xIX era condenado por monárquicos y republicanos, pero también aludía a un estilo como persona pública. ${ }^{30}$ Su entrada en los círculos intelectuales de la ciudad de México, con su celebrada presentación en la Academia de Letrán, en la que afirmó la inexistencia de Dios, fue un performance tanto como una provocación filosófica, como lo recordaría el mismo Prieto, que era miembro fundador de la Academia. Desde entonces Ramírez combinaba la elevación filosófica de sus ideas con una apariencia desaliñada, de porte desgarbado y ropa vieja. Sus intercambios sardónicos con amigos y adversarios oscilaban, como su poesía, entre el insulto y la autocrítica. ${ }^{31}$ Los escritos de Ramírez en Don Simplicio reinterpretaban esa tradición revolucionaria como un proyecto didáctico que buscaba dar instrumentos al pueblo para encontrar esa "verdad deliberada". Esto significaba establecer una nueva forma de representación política basada en la correspondencia entre el lenguaje y la realidad y mediada por una discusión tan desordenada como abierta.

En verso y prosa, Ramírez reflexionó en Don Simplicio sobre la libertad de discusión, la relación entre individuo, mayorías y poder, y sobre la utilidad como criterio cardinal de cualquier sistema político. Para Ramírez, el monarquismo y la equivalente abstracción del republicanismo suponían, erróneamente, que la soberanía podía estar concentrada en unos pocos iluminados. Por el contrario, afirmaba, la inteligencia estaba repartida en toda la población. En "La soberanía de la inteligencia", dedicado a El Tiempo en marzo de 1846, Ramírez criticaba al sistema europeo "donde / el que

${ }^{30}$ Ramírez reconocía la etiqueta de jacobino de parte de otros autores. Así lo llamaba Vicente Segura Argüelles, otro colaborador, en "Primer caústico de Pablo de Cantárida. Hombres de importancia”, Don Simplicio, t. 1, n. 1, diciembre de 1845, p. 6; Nigromante, "La representación nacional", Don Simplicio, t. 1, n. 1, diciembre de 1845, p. 6. El mejor tratamiento sobre el seudónimo en Liliana Weinberg, "La palabra de la Reforma en la república de las letras", en Ignacio Ramírez. La palabra de la Reforma en la república de las letras. Una antología general, México, Fondo de Cultura Económica/Fundación para las Letras Mexicanas/Universidad Nacional Autónoma de México, 2009.

${ }^{31}$ A un tal Alcaraz le decía compañero de desgracia porque los dos, según Prieto, eran feos. Prieto, Obras completas, t. 1, p. 372. 
hace versos es conde, / con tal de que tenga ropa" y "donde todo el que hace un drama, / es apto para hacer leyes". En una verdadera república, por el contrario, "a todo el pueblo su influencia / extienda la inteligencia". El saber es compartido por muchos, cada uno según su lugar y sus intereses: el que sabe de Tabasco no conoce Sonora. La conclusión del poema era una profesión de escepticismo político que evocaba el individualismo pero también el sentido común:

Pues según eso, así argullo:

Ocúpese cada cual

de lo que haga menos mal.

Y ¿qué sabrá más? lo suyo. ${ }^{32}$

"Pronunciamiento de Don Simplicio", publicado sin firma en el primer número del periódico, y probablemente escrito en colaboración con Prieto, extendía el escepticismo al estilo del discurso político. La crítica era doble al parodiar el estilo de los pronunciamientos políticos que usaban los rebeldes de toda laya. El "plan" era una lista de peticiones imposibles ("Art. antepenúltimo. Todo general deja de serlo, si á juicio de tres profesores de primeras letras, no sabe leer ni escribir corrientemente [...] Art. cuarto. Damos dado Tejas á los yanquees con tal de que remitamos para allá lo que aquí nos sobra, y no le permitan la salida"). Esto significaba poner en duda las certidumbres del pronunciamiento como texto político: "Compatriotas", decía "Don Simplicio", "el plan que he proclamado no es la expresión de la voluntad nacional, por la sencilla razón de que no la conozco, y lo confieso, me atrevo a dudar que exista". ${ }^{3}$

${ }^{32}$ Nigromante, "La soberanía de la inteligencia. Al tiempo", Don Simplicio, t. 2, n. 19, 4 de marzo de 1846, p. 3.

33 "Pronunciamiento de Don Simplicio. Manifiesto", Don Simplicio, t. 1, n. 1, diciembre de 1845 , p. 3-4. Para un estudio del pronunciamiento como práctica política y como texto que decía representar la voluntad popular Will Fowler, Forceful Negotiations: The Origins of the Pronunciamiento in Nineteenth-Century Mexico, Lincoln, University of Nebraska Press, 2010. Sobre el proyecto de formar una ciudadanía participativa "desde abajo" en Don Simplicio, véase Sánchez Archundia, Desde la Asnópolis..., p. 159-176. Véase también Cérida Webster Henestrosa, Don Simplicio y el proyecto de nación liberal social, tesis de licenciatura en Historia, México, Universidad Nacional Autónoma de México, 2006. Según Fowler, el pronunciamiento era una forma deliberativa que empezaba en una conspiración pero servía para ampliar la influencia de diversos actores mediante su acceso a la palabra escrita, y su 
Contra una idea abstracta de la soberanía, Ramírez proponía una democracia individualista basada en la premisa de que la igualdad concernía a la inteligencia más que a los derechos. Ignorar esta realidad era la razón por la que "media docena de constituciones" hubieran fracasado. ${ }^{34}$ Contra la creencia de sus contemporáneos en el diseño constitucional como solución a los problemas nacionales, Ramírez ofrecía un pragmatismo casi ofensivo por lo prosaico. No puede haber leyes inmutables, decía en "i¡Una constitución estable!!”, de febrero de 1846:

\section{Mudar de constituciones, será un mal, pero forzoso, como mudar de calzones. ${ }^{35}$}

Para Ramírez, pensar que un grupo de letrados podía decidir qué calzones debía usar permanentemente el país era un acto de infundada soberbia. En “iLa futura constitución!” combinaba verso y prosa para argumentar que cualquier contrato podía ser roto cuando una de las partes era débil.

Que la constitución futura sea federal, central, monárquica, o como pronostican malas lenguas, teocrático-militar, me importa un pito y cien trompetas; porque hemos llegado al caso de no investigar cuál gobierno es el mejor, sino cual podrá sostenerse en nuestra patria. ${ }^{36}$

El argumento contra el legalismo de los ideólogos era sencillo: "la cuestión [...] no es de gobierno, sino de bolsillo". ${ }^{37}$ En un ensayo "Sobre la inmutabilidad de las leyes" Ramírez sonaba como un Rousseau amargado: "La mayor parte de los hombres heredamos miseria y conservamos cuidadosamente el modo con que nuestros abuelos se hicieron miserables". Las cadenas que los mexicanos se imponían para seguir siendo miserables, según

popularidad se derivaba de la ausencia de otras formas de representación. Fowler, Forceful Negotiations..., p. 248, 250, 257.

${ }^{34}$ Nigromante, “A los viejos", Don Simplicio, t. 1, n 1, diciembre de 1845, p. 2.

${ }^{35}$ Nigromante, “iiUna constitución estable!!”, Don Simplicio, t. 2, n. 11, 4 de febrero de 1846, p. 4.

${ }^{36}$ Nigromante, “iLa futura constitución!”, Don Simplicio, t. 2, n. 5, 14 de enero de 1846, p. 3-4.

${ }^{37}$ Nigromante, “Utilidad del tiempo”, Don Simplicio, t. 2, n. 20, 7 de marzo de 1846, p. 2. 
Ramírez, eran leyes que aceptaban sin pensar ni debatir - lo opuesto de la "verdad deliberada". 38

\section{Proyecto literario}

La contraparte de esta crítica a las ideologías políticas en Ramírez era una poética que evadía las categorías de la historia literaria basadas en la distinción entre románticos y neoclásicos. Los primeros ofrecían un programa que daba al poeta y a la poesía un lugar central en la transformación del lenguaje y por lo tanto la sociedad. Una de las versiones del romanticismo disponibles en México de los cuarenta era la que formuló y ejemplificó el escritor francés Víctor Hugo, y que veía al poeta como profeta y a la poesía como revelación de la libertad. En 1827, Hugo publicó un prefacio a su obra de teatro sobre Cromwell en el que presentaba un esquema histórico de la evolución de la poesía, desde la épica de los clásicos hasta la lírica que definía los tiempos contemporáneos. Más allá de las escuelas, la literatura, según Hugo, avanzaba gracias al impulso de los genios, cuyo papel era definir su momento y abatir los dogmas. Los poetas debían abolir el uso de las reglas heredadas y utilizar sólo las que respondieran a las condiciones específicas de cada tema. Como el lenguaje cambiaba con la sociedad, decía Hugo, los poetas no debían copiar a nadie sino usar múltiples fuentes de inspiración y expresar su propia personalidad. ${ }^{39}$ Contemporáneos como Hugo y Lord Byron proyectaban desde Europa un aura de sacerdotes de las

${ }^{38}$ Ramírez, "Sobre la inmutabilidad de las leyes”, 262-264, Don Simplicio, t. 2, n. 27, 1 de abril de 1846, p. 2 y 3. Rousseau había dicho en El contrato social: "El hombre ha nacido libre, y en todas partes se halla entre cadenas". Jean-Jacques Rousseau, Du contrat social, ou principes du droit politique. Collection complète des oeuvres, Genève, 1780-1789, Paris, Le Pléiade, 1866 (disponible en http://www.rousseauonline.ch/Text/du-contrat-social-ou-principes-du-droit-politique.php), libro 1, cap. 1, p. 190. Todavía en 1868, año en que Ramírez fue nombrado ministro de la Suprema Corte, escribía que "Todas las teorías, todas las instituciones, todas las leyes del sistema administrativo no tienen sino un objeto visible: alucinar a los parias con poesía, consolarlos con el estoicismo, contenerlos y escarmentarlos con seguras e inhumanas penas". Citado en Monsiváis, “La expresión radical de Ignacio Ramírez...”, p. x. Originalmente en "Principios sociales y principios administrativos", 1868. Texto completo en Ramírez, Obras de Ignacio Ramírez..., v. 2, p. 5-9.

${ }^{39}$ Prefacio a Cromwell, en Victor Hugo, Oeuvres complètes de Victor Hugo, Paris, Hetzel-Quantin, 1880, p. 17, 25, 27, 35. Sobre romanticismo en México, véase Carlos Illades, Nación, sociedad y utopía en el romanticismo mexicano, México, Consejo Nacional para la Cultura y las Artes, 2005. 
ideas liberales. ${ }^{40}$ Otra versión del programa romántico la presentaba Alphonse de Lamartine en un ensayo de 1834 traducido al español en El Año Nuevo, el órgano de la Academia de Letrán, en 1840. La poesía, para Lamartine, era "la lengua completa, la lengua por excelencia que se apodera del hombre avasallando todo su ser". El verso era una forma superior porque "La prosa no se dirige más que a la idea; el verso habla a un mismo tiempo a la idea i a la sensación”. La poesía estaba destinada a ser personal pero también "será filosófica, religiosa, política i social". Esta capacidad totalizadora, según Lamartine, se derivaba del origen divino de la poesía ("Dios mismo se la ha dado" al hombre). Políticamente, esto implicaba una jerarquía estricta, tanto sagrada como social. El pueblo, según Lamartine, tenía necesidad de la poesía, pero ésta era todavía "la voz de la humanidad pensadora". Es decir, Lamartine se situaba, y situaba a los lectores de El Año Nuevo, en una posición muy clara respecto del pueblo: "a nosotros toca [...] explicarle, por medio de sus afectos expresados en su idioma, la bondad, nobleza, generosidad, patriotismo i piedad entusiasta que Dios ha puesto en su corazon". ${ }^{41}$

En los años cuarenta, sin embargo, todavía prevalecía en México una concepción de la poesía impregnada por los modelos clásicos. Los exponentes mexicanos del neoclasicismo, incluyendo varios miembros de la Academia de Letrán, se preocupaban por la función patriótica de la poesía en un marco que enfatizaba las jerarquías del saber y las diferencias sociales. En un escrito de 1844 que respondía al texto de Hugo citado arriba, Luis de la Rosa definía a la poesía como "esas composiciones [...] escritas con cierta elevación más o menos sublime, porque hay en ellas imágenes o concepciones brillantes y fantásticas; porque describen objetos de los que no se puede dar idea en el lenguaje común; porque infunden afectos y pasiones, que nunca se pueden transmitir con una locución vulgar y lánguida”. Imitar la naturaleza, buscar lo bello, "leer todo lo que los grandes poetas han escrito antes que él” eran las obligaciones del poeta. Esta capacidad para decir lo

${ }^{40}$ Weinberg, "La palabra de la Reforma en la república de las letras...”, p. 19; Monsiváis, “La expresión radical de Ignacio Ramírez...”, v. 3, p. XıII. Difiero en esto de Andreas Kurz, "Ignacio Ramírez o el amor/odio romántico a la autoridad", Estudios: Filosofía, Historia, Letras, v. XII, n. 108, primavera de 2014, p. 148-150.

${ }^{41}$ Alfonso de Lamartine, "Sobre los destinos de la poesía”, en Eulalio María Ortega (ed.), El año nuevo de 1840. Tomo IV. Edición facsimilar, México, Universidad Nacional Autónoma de México, 1994, p. 203-205, 230, 232-233). Véase Domínguez Michael, La innovación retrógrada..., p. 204. 
que otras formas del lenguaje no podían decir establecía, para De la Rosa, una unión entre poesía y nación. Cuando la patria sea feliz, afirmaba, los poetas mexicanos serán los mejores del mundo y tendrán completa originalidad. Mientras tanto, sentenciaba, "En donde no hay patria, no hay verdadera poesía”. ${ }^{42}$ Estas influencias podían aparecer mezcladas.

Ramírez no adoptó ninguno de estos modelos porque su programa político y literario negaba la centralidad del poeta y la jerarquía didáctica que proponían Lamartine y De la Rosa. Como a muchos de sus contemporáneos, el intimismo y el misticismo románticos eran imposibles en un contexto histórico en el que, como señala Luis Miguel Aguilar, la poesía quedaba “desbordada por los acontecimientos". ${ }^{43}$ La sátira de Ramírez, en cambio, separaba la inspiración de la función social de la literatura. Ramírez partía de una definición más abarcadora, que veía a la poesía como una práctica social, independientemente de la personalidad del poeta. Contra el formalismo de los neoclasicistas y la visión religiosa de Hugo y Lamartine, Ramírez postulaba que la forma y el significado se constituían mutuamente en la comunicación entre actores sociales. Ramírez partía de un impulso igualitario y ateo en el que la inspiración era menos importante que la comunicación, y en el que no se asumía la inferioridad intelectual del pueblo. Sin embargo, compartía la premisa común de que la poesía expandía la capacidad del lenguaje y por lo tanto su valor político.

Ramírez y los redactores de Don Simplicio creían que la poesía podía cambiar la historia y, con sus reservas, que los poetas podían tener una función en la vida pública. ${ }^{44}$ Para Guillermo Prieto, esto significaba escribir

${ }^{42}$ Luis de la Rosa, “Utilidad de la literatura en México”, en Jorge A. Ruedas de la Serna (coord.), La misión del escritor. Ensayos mexicanos del siglo XIX, México, Universidad Nacional Autónoma de México, 1996, p. 93, 96, 97, 103, 101. De la Rosa fue liberal y antimonarquista, ministro de Hacienda con Herrera.

${ }^{43}$ Luis Miguel Aguilar, La democracia de los muertos, México, Cal y Arena, 1988, p. 109, 115. En la historia literaria, la transición entre neoclásicos y románticos es el eje dominante, y la construcción de una literatura nacionalista el destino inevitable de la obra juvenil de Ramírez y su generación. Ramírez como romántico influido por Byron en Domínguez Michael, La innovación retrógrada..., p. 503; romántico por su contexto político en Aguilar, La democracia de los muertos..., p. 108-109; prerromántico en Weinberg, "La palabra de la Reforma en la república de las letras...”, p. 17; neoclásico en Manuel Gutiérrez Nájera, Obras, ed. de José Luis Martínez, México, Fondo de Cultura Económica, 2003, p. 452.

${ }^{44}$ Para otros casos en que "the redemptive power of language as a means of altering the course of history. [...] For them politics was very much a part of the poet's domain”, véase Edward Ousselin, "Victor Hugo's European Utopia”, Nineteenth-Century French Studies, v. 34, 
una poesía liberal en su proyecto político y mexicana en sus temas y vocabulario. En contraste, la fe de Ramírez en el poder político del lenguaje incluía una crítica a la concepción enaltecida del poeta como genio. Ramírez no había publicado poesía antes de Don Simplicio, ni siquiera en El Año Nuevo, el órgano de la Academia de Letrán. ${ }^{45}$ Hacia mediados de los cuarenta, como veremos en detalle más adelante, Ramírez albergaba una visión poco benévola de la poesía contemporánea, a la que veía subordinada a un estéril y obsesivo clasicismo. Sin embargo, reconocía que acudir a ella era inevitable en ese momento de crisis. El verso le ofrecía el mejor vehículo para representar la diversidad de voces y públicos que participaban en la expansión del debate público. La sátira, en particular, le permitía atacar a sus enemigos y al mismo tiempo representar sus opiniones a través de diálogos. Más importante tal vez, el efecto humorístico de la sátira, la satisfacción de reírse de los hombres públicos y las costumbres nacionales, era una manera de apelar a la inteligencia de los lectores y moverlos a actuar. La poesía, en otras palabras, servía para expandir el público, pero también el lenguaje de la política. ${ }^{46}$

No es coincidencia entonces que, además de empezar a publicar versos, Ramírez comenzara en Don Simplicio una reflexión teórica sobre la literatura y el lenguaje. Esta teoría, que podemos entresacar de poemas y ensayos en Don Simplicio, enfatizaba una perspectiva crítica hacia los movimientos literarios que entonces se disputaban la hegemonía. ${ }^{47} \mathrm{Su}$ énfasis en temas sociales no requería, como en Hugo, de un poeta iluminado. Su interés por la tradición clásica no le impedía desdeñar la erudición. Como poeta, Ramírez ponía a la ciencia por encima de lo divino, negaba el papel religioso del poeta, y despreciaba la búsqueda de las emociones íntimas. ${ }^{48}$

n. 1/2, 2005. Citando a Suzanne Nash, Les Contemplations of Victor Hugo: An Allegory of the Creative Process, Princeton, Princeton University Press, 1976, p. 17.

${ }^{45}$ Fernando Tola de Habich, "Prólogo", en El año nuevo de 1837. Tomo I. Edición facsimilar, México, Universidad Nacional Autónoma de México, 1996, p. cxv.

${ }^{46}$ Para una discusión de los antecedentes y los mecanismos de la sátira en Don Simplicio, véase Sánchez Archundia, Desde la Asnópolis..., p. 64 y s.

${ }^{47}$ Christopher Domínguez Michael y Fernando Tola de Habich opinan que Ramírez fue el primer teórico literario mexicano. Tola de Habich, "Prólogo", en El año nuevo de 1837...; Domínguez Michael, La innovación retrógrada..., p. 504.

${ }^{48}$ John Skirius, "Pensamiento cultural y educativo de Ignacio Ramírez", en La palabra de la Reforma en la república de las letras. Una antología general. México, Universidad Nacional Autónoma de México, 2009, p. 449-459, cita en p. 449; Castro, "Ignacio Ramírez, lecturas 
Un concepto que no aparecía todavía en Don Simplicio pero que Ramírez desarrollaría poco tiempo después fue el del lenguaje de acción. Ramírez lo definía como una forma básica de comunicación que iba más allá de las palabras y el texto, como lo que hoy llamaríamos un performance que incluía los gestos, el silencio y el ritmo. ${ }^{49}$ La poesía, según Ramírez, era el vehículo más importante del lenguaje de acción porque usaba "el metro, la rima y el canto". Al convertir las ideas en acción, permitía a la sociedad establecer vínculos naturales basados en la comprensión mutua. Ramírez expuso estas ideas en las lecciones de literatura que dio desde mediados de los cincuenta y a las que regresaré más adelante. Allí definía el lenguaje de acción como los actos corporales que se utilizaban para expresar pensamientos que carecían de vocabulario. En otras palabras, el lenguaje de acción era anterior a "todas las naciones y todos los siglos" pero también era, en el presente, la forma que adquiría "la tempestad de las pasiones" que daba su poder a la elocuencia tribunalicia. ${ }^{50}$ Esta teoría sobre el origen del lenguaje llevaba lógicamente a medir el valor de la literatura por su eficacia y no a partir de un canon o un género. Ramírez afirmaba que el "lenguaje vulgar" usado por la muchedumbre era perfecto en su gramática, aunque no fuera bello en su expresión. ${ }^{51}$ Los poemas de Don Simplicio, más cotidianos que sublimes, más originales que derivativos, prueban que el verso era para Ramírez la forma más elevada del lenguaje de acción y, por lo tanto, de la comunicación entre ciudadanos y gobierno en un momento de crisis.

pendientes...”, p. 413-435, cita p. 424. Aunque esto último cambió en su poesía lírica de madurez, todavía entonces predecía el desprecio de la posteridad hacia los "románticos y espiritualistas y culteranos". Ignacio Ramírez, "Discurso leído en la sesión que el Liceo Hidalgo celebró en honor de D. José Joaquín Fernández de Lizardi”, 1874, Ramírez, Obras de Ignacio Ramírez, p. 297.

${ }^{49}$ Ramírez, “Dos lecciones inéditas sobre literatura” [1855], en Ramírez, Obras de Ignacio Ramírez, v. 1, p. 300.

${ }^{50}$ Ramírez, Obras de Ignacio Ramírez, v. 1, p. 300; Elías Palti, La invención de una legitimidad..., p. 352, 369, 373, 378-379, 393. La obra de Ramírez "es una expresión característica de un momento de inflexión político-conceptual, de inestabilidad de los lenguajes”. Palti sigue esta pista a través de los escritos linguiísticos de Ramírez y la teoría fisiológica consonante con ideas políticas positivistas que Ramírez adoptaría hacia el final de su vida. Palti, La política del disenso..., p. 47.

${ }^{51}$ Ramírez, "Dos lecciones inéditas sobre literatura” [1855], en Ramírez, Obras de Ignacio Ramírez, v. 1, p. 299. 


\title{
Inteligencia soberana
}

Esta poética se reflejó en los escritos de Ramírez en Don Simplicio de manera negativa a través de sus ataques contra la religión y el patriotismo, dos áreas donde no había mucha controversia entre las facciones ideológicas de entonces. El ateísmo distinguió a Ramírez de sus contemporáneos liberales. En su presentación ante la Academia de Letrán afirmó que "No hay Dios; los seres de la Naturaleza se sostienen por sí mismos". Esa tesis fue el punto de partida de una batalla intelectual algo quijotesca contra la retórica y la inmoralidad religiosas que no podríamos reducir, sin embargo, a un simple anticlericalismo ilustrado. En Don Simplicio, Ramírez llevó esa crítica a terrenos que el discurso político generalmente no tocaba. El ateísmo de Ramírez implícitamente criticaba a aquellos liberales que condenaban al partido clerical pero que al mismo tiempo mantenían en su lenguaje y su vida cotidiana mucho del moralismo católico. ${ }^{52}$

Un aspecto de este moralismo era la economía del castigo y el deseo. En una "Carta al Diablo" de febrero de 1846, el Nigromante proponía que la obsesión cristiana con el castigo nunca podría contrarrestar los atractivos del oro y el placer. ${ }^{53} \mathrm{El}$ poema tenía la forma de una misiva en la que el Nigromante se dirigía al Diablo (a quien llamaba "Dueño mío" u "ó satán”). El autor reportaba lo dicho por un tercer personaje, un cura vociferante y sudoroso que desde el púlpito afirmaba que sólo el temor al infierno mantenía la moral entre los hombres. El poema está hecho de trece sextetos de octosílabos en los que el tercer y sexto versos, truncados a la mitad, marcaban el ritmo. Las restricciones de la forma y la dualidad de voces obligaban a que el lenguaje fuera más sintético y menos natural que el diálogo de "La representación nacional”, pero no por ello menos rítmico:

\author{
Y dijo: Si no temieran \\ el infierno los cristianos, \\ criminales \\ de seguro todos fueran, \\ se mataran los hermanos \\ por dos reales.
}

\footnotetext{
${ }^{52}$ Monsiváis, "La expresión radical de Ignacio Ramírez...”, p. viII-IX. Sobre la Academia de Letrán, Tola de Habich, "Prólogo...”.

${ }^{53}$ Nigromante, "Carta al diablo", Don Simplicio, t. 2, n. 12, 7 de febrero de 1846, p. 2.
} 
El Nigromante le aconsejaba al Diablo que en lugar de castigo en el infierno ofreciera placeres.

Pon una mesa de juego.
La bella oro, los varones
tengan bellas.
Si así pones el abismo,
será todo hombre de bien
pecador. ${ }^{54}$

Además del deseo, la religión intentaba detener la inteligencia. Para Ramírez, por el contrario, placer e inteligencia estaban ligados positivamente. En poemas como "La representación nacional" y "Carta al Diablo", las insinuaciones sexuales y los ejemplos de corrupción clerical le permitían proponer que la religión católica y el legalismo aristotélico que de ella heredaba la vida pública eran obstáculos para que el pueblo discutiera libremente sobre lo que de veras le importaba, y que no era siempre lo más santo. ${ }^{55}$

Otro ejemplo de esa expansión del discurso público mediante el verso son los ataques de Ramírez en Don Simplicio contra el patriotismo. En los momentos en que la nación era invadida y los mismos lectores del periódico mandaban composiciones patrióticas contra los norteamericanos, Ramírez se burlaba de aquellos que intentaban preservar la integridad territorial aunque no supieran dónde quedaba Texas. ${ }^{56}$ Un texto en prosa de enero de 1846, "Las esperanzas de la patria", listaba las modalidades de la ridiculez patriótica: había los que rechazaban la colonización por pura xenofobia, los gobernantes que se la pasaban intrigando pero eran incapaces de organizar la defensa, y los jóvenes de clase alta que tenían ambiciones

${ }^{54}$ Nigromante, “Carta al diablo", Don Simplicio 2, n. 12, 7 de febrero de 1846, p. 2. Su obra posterior contiene varios poemas en los que afirma que la fe religiosa es una manera de reemplazar o desviar el deseo sexual. Véase “Décimas" [1866] en Ramírez, Obras de Ignacio Ramírez, v. I, p. 57-58.

${ }^{55}$ En poemas posteriores Ramírez también identificaba la religión católica con la estupidez clerical, el despojo colonial, la retórica exagerada, y una hipocresía sexual que contaminaban tanto la vida privada como la pública. "El mito cristiano", 1874, en Ramírez, La palabra de la Reforma en la república de las letras..., p. 380.

${ }^{56}$ Nigromante, “Tejas”, Don Simplicio, t. 2, n. 2, 3 de enero de 1846, p. 1. Sobre la ausencia de patriotismo en la teoría literaria de Ramírez, véase Martínez Carrizales, "Ignacio Ramírez, teórico de la literatura...”, p. 442. 
pero nunca "serán héroes". ${ }^{57}$ Todos compartían la responsabilidad. En "Un pueblo de máquinas", un poema en endecasílabos de ese mismo mes, Ramírez afirmaba que los mexicanos, en general, eran culpables de la inevitable derrota porque les gustaba demasiado el baile y la música, las joyas y las peleas, y porque preferían las fiestas parroquiales a tender el alumbrado. ${ }^{58}$ Dos estrofas definían el fracaso nacional:
Zahurda y no nación hemos formado
nuestro espíritu público defino,
lo que no es, pues, no existe ni el privado.
El pueblo es en su patria peregrino, hora está defendiendo sus linderos, sólo por molestar a su vecino. ${ }^{59}$

Algunas ilustraciones y poemas de Prieto también en Don Simplicio caricaturizaban la baja moralidad del liderazgo militar (figura 3). Esta visión negativa de las costumbres de los mexicanos y su costo para la integridad nacional la compartían muchos, aunque no la publicaban con tanto desenfado. ${ }^{60}$

El avance de la guerra no detuvo la sátira antinacionalista. En "Una colonia", de julio de 1846, Ramírez presentaba una lista de nombres ficticios de los que irían a colonizar la Alta California (por ejemplo, "D. Gordiano Mantecón de la Cerda [...] Tocinero", "D. Canuto Frías [...] Nevero", "D. Dolores Reygadas [...] Dentista"). A la lista seguían cuartetas irregulares sobre la futilidad de un patriotismo que no tenía bases materiales, pero celebraba el clericalismo y el militarismo:

57 "Las esperanzas de la patria", Don Simplicio, t. 2, n. 4, 10 de enero de 1846, p. 1, en Rosen y Maciel, Obras completas de Ignacio Ramírez..., v. 1, p. 186.

58 "Un pueblo de máquinas", Don Simplicio, t. 2, n. 9, 28 de enero de 1846, p. 2.

59 "Un pueblo de máquinas", Don Simplicio, t. 2, n. 9, 28 de enero de 1846, p. 2.

${ }^{60}$ Carlos María de Bustamante, que por otro lado esperaba que la protección divina protegiera a México ante los invasores, escribía en su diario en mayo de 1845, para explicar la falta de preparación ante el inminente ataque, "Que somos para nada buenos... Que no sabemos más que beber nuestro pulque, comer enchiladas, bailar cuadrillas y galopar, echar albures en San Agustín de las Cuevas y charlar con las damiselas en los estrados. Esto, en buen castellano y dispensándome los oídos piadosos, se llama ser unos... Pendejos, con P grande”. Bustamante, Diario histórico de México, 1822-1848..., entrada de 17 de mayo de 1845. 


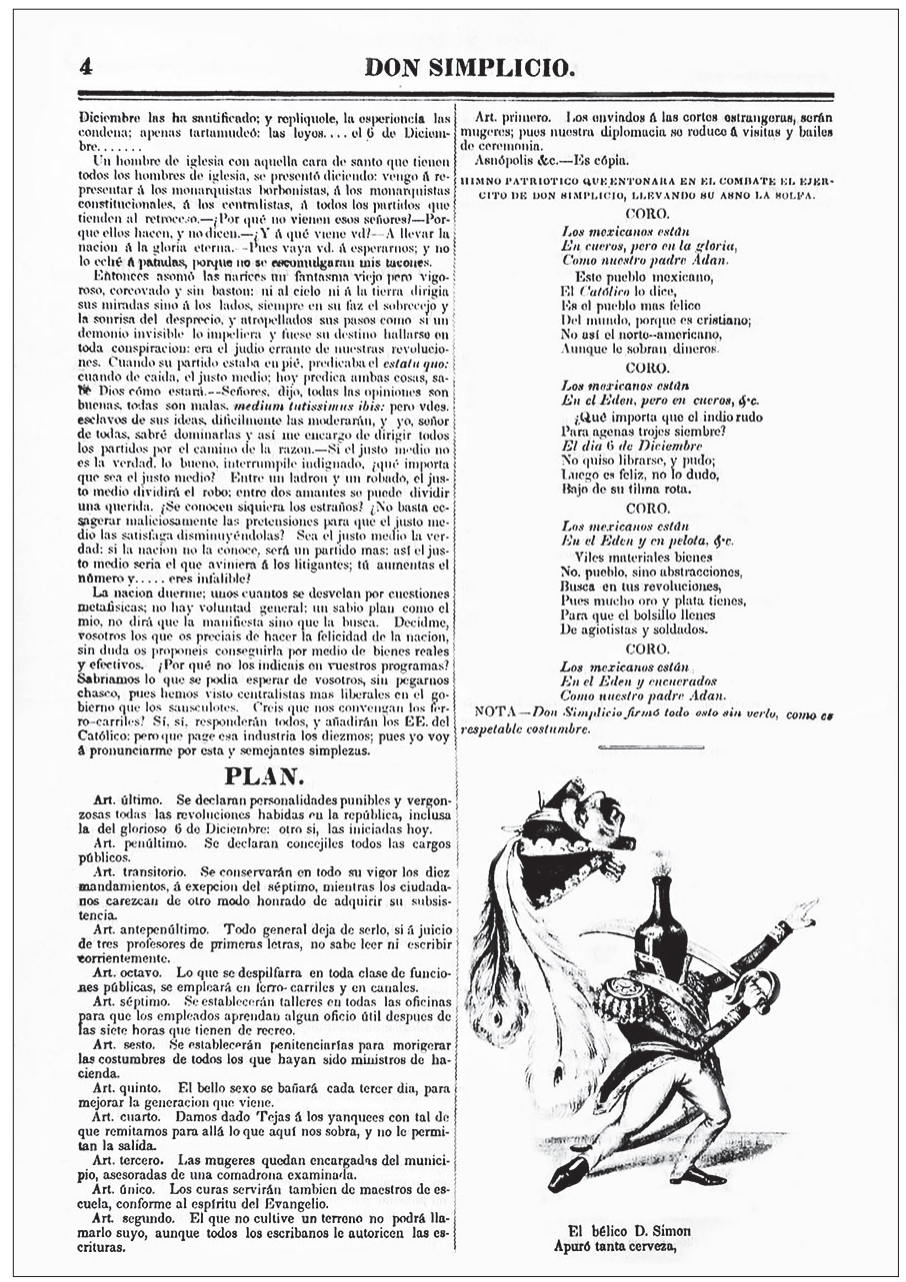

Figura 3. Caricatura de militar con cabeza de botella. Fuente: Don Simplicio, enero de 1845

\section{¿Qué importa que esté atrasada Nuestra civilización \\ Mientras tenga la nación \\ Un bonete y una espada? ${ }^{61}$}

${ }^{61}$ Nigromante, “Una colonia”, Don Simplicio, t. 3, n. 8, 25 de julio de 1846, p. 2. Bajo el seudónimo de Cantárida, Vicente Segura Argüelles también se burlaba de los militares y su gusto por el alcohol. "Escala patriótica”, Pablo Cantárida [Vicente Segura Argüelles, fechado 12 de septiembre de 1845], Don Simplicio, t. 2, n. 3, 7 de enero de 1846, p. 2-3. 
Ni siquiera las tropas que iban a luchar contra los invasores se salvaban. En "Canto marcial de un hijo de Don Simplicio que va de vivandero en la expedición que ha salido últimamente de México, contra los norteamericanos", el coro señalaba la desorientación de la defensa nacional, que no encontraba al enemigo ni se alejaba de la capital:

en dos meses,

tanto ha sido nuestro afán

que en su busca, y sin hallarlos,

llegamos a Cuautitlán. ${ }^{62}$

"Las botas", de agosto de ese año, describía los fingidos esfuerzos de curas, periodistas y empleados para ponerse una bota (y simbólicamente convertirse en soldados en campaña):
A vengar nuestras derrotas
marchan ya nuestros valientes,
esperando están las gentes
a que se pongan las botas. ${ }^{63}$

Este poema definía el momento político en todas sus contradicciones. Personajes fáciles de identificar para los lectores, aunque sus nombres no estuvieran impresos, eran responsables de la derrota inminente. La referencia a Santa Anna, que sólo necesitaba una bota, no era demasiado clara en ese momento, tal vez por precaución. Desde el año 1845 circulaban rumores sobre una conspiración para que el caudillo veracruzano regresara a ponerse al frente de la defensa, como eventualmente lo haría. Parte de su plan era promover el regreso al federalismo con el apoyo de la prensa. ${ }^{64}$

${ }^{62}$ Nigromante, "Canto marcial de un hijo de Don Simplicio que va de vivandero en la expedición que ha salido últimamente de México, contra los norteamericanos”, Don Simplicio, t. 3, n. 38, 22 de julio de 1846, p. 3.

63 “Las botas", Don Simplicio, t. 3, n. 10, 1 de agosto de 1846, p. 3.

${ }^{64}$ Como el ateísmo, esta crítica al nacionalismo no sería un tema pasajero en Ramírez. En su obra posterior, aún en los momentos más álgidos de la celebración de la derrota del imperio en 1867, Ramírez se negó a reivindicar el patriotismo como puro sentimiento. "A la Patria”, de 1868, celebra la paz y la derrota del enemigo, pero reconoce la debilidad de la república, deseando que nunca más la patria tenga que ser salvada por "Don Benito" (Ramírez, Obras de Ignacio Ramírez, v. 1, p. 15-16). Sobre la conspiración, véase Anónimo a MPA, México, 22 de octubre de 1845, BLAC, MPAP, exp. 143 D, doc. 392. Los planes de Santa Anna en Santa Anna a Manuel 
Sin ser mencionado, Paredes y Arrillaga era una alusión más obvia en Don Simplicio.

El placer de la risa

Sería insuficiente quedarnos en una lista de los aspectos negativos de la crítica de Ramírez al lenguaje y las ideologías políticas vigentes en ese momento de crisis. El ataque contra los adversarios monarquistas, mochos y militaristas era la base de una concepción de la literatura radicalmente nueva y un programa que en los años siguientes Prieto y Ramírez se encargarían de poner en práctica a su manera.

Así, por ejemplo, la polémica contra los monarquistas de El Tiempo rayaba en el insulto y se nutría de la xenofobia, pero remitía también a un proyecto político de apropiación del lenguaje. En varios textos de Don Simplicio, Ramírez presentaba una observación que sus lectores probablemente compartían: los españoles parecían poseer cierta superioridad cultural porque estaban en "la ilustrada Europa" (dice en "El Espectador y Don Simplicio"). ${ }^{65}$ Pero esta superioridad no era más que luz refleja. En un poema de 1850 ("Contra los españoles que redactan El Huracán"), Ramírez afirmaba que los redactores de ese periódico eran "ignorantes traductores" cuya ventaja, como peninsulares, consistía en poner sus manos en las obras de Eugenio Sue y Hugo antes que los mexicanos.

Odio á esas gentes cuya ciencia sola consiste en cierto acento estrafalario, y en decir $l l$ y $z$ á la española.

Sé lo bastante de su abecedario para arrojarles en su faz inmunda cuanta injuria me dé su diccionario. ${ }^{66}$

Teulet, 8 de marzo de 1846, BLAC, VGFC, fólder 49, doc. 1377, y Antonio López de Santa Anna a Gómez Farías, El Encero, 21 de agosto de 1846, BLAC, VGFC, fólder 49, doc. 1590.

${ }^{65}$ Nigromante, “El Espectador y Don Simplicio”, Don Simplicio, t. 2, n. 15, 18 de febrero de 1846, p. 4.

66 "Contra los españoles que redactan El Huracán” [1850], en Ramírez, Obras de Ignacio Ramírez, v. 1, p. 59. Véanse notas sueltas sobre los españoles en Biblioteca INAH, Fondo Ignacio Ramírez, microfilm, rollo 4. 
Los insultos incluían ataques a la masculinidad de los españoles: Ramírez proponía quitarles sus mujeres ("es consumar la independencia"), e insinuaba que la reina de España tenía amores ilícitos. ${ }^{67}$ Este sexismo, debemos recordar, no era una patología sino un componente central de todo proyecto literario nacional en esos años: las mujeres no escribían y si lo hacían debían parecer hombres al hacerlo; su influencia y su libertad excesiva hacían vulnerable al honor privado y por extensión al nacional. ${ }^{68}$

El alegato antiespañol contenía una reflexión sobre lenguaje y política. En una carta dirigida al Nigromante, publicada en agosto de 1846, "el Diablo" (interlocutor ficticio, probablemente el mismo Ramírez), afirmaba que la burla era necesaria porque "Los hombres son hijos de las palabras”, y pueden ser fácilmente manipulados por ellas y por etiquetas políticas que no significan nada. ${ }^{69}$ Lo que hay que reconocer, escribía Ramírez en "Utilidad del Tiempo", un ensayo publicado en marzo 1846, es que los monarquistas han dado una lección a los republicanos mexicanos con su capacidad para hacer progresar sus malas ideas ante la opinión pública. Promover la monarquía en la prensa era parte de una ofensiva que incluía la guerra: "hoy nos combate con papeles, para combatirnos después con balas". ${ }^{70}$ En efecto, la estrategia de los inspiradores de El Tiempo, Alamán y Bermúdez de Castro, era influir sobre la opinión pública para permitir el establecimiento del monarquismo a través de una asamblea nacional. Así lo anunciaron el 12 de febrero de 1846 y no antes, explicaron, "porque obramos con arreglo a un plan" que empezaba por "tantear la opinión". ${ }^{71}$ Como señalan varios historiadores, la polémica sobre la monarquía de los años cuarenta inauguró una nueva era en la esfera pública mexicana, caracterizada por la manipulación estratégica de

67 "Contra los españoles que redactan El Huracán" [1850], en Ramírez, Obras de Ignacio Ramírez, v. I, p. 61.

${ }^{68}$ Véase, además de las descripciones de "el poeta” citadas en este artículo, Ignacio Manuel Altamirano, "Carta a una poetisa" [1871], publicado en El Domingo, t. 2, n. 10, 31 de marzo y 7 de abril de 1872, en Ignacio Manuel Altamirano, Obras completas. XIII. Escritos de literatura y arte, tomo 2, ed. José Luis Martínez, México, Secretaría de Educación Pública, 2011, p. 45-73.

${ }^{69}$ Nigromante, "Cartas del diablo al Nigromante, Don Simplicio, t. 3, n. 16, 22 de agosto de 1846, p. 2.

70 Ramírez, "Utilidad del Tiempo", Don Simplicio, t. 2, n. 20, 7 de marzo de 1846, p. 2-3.

71 "Nuestra profesión de fe", El Tiempo, t. 1, n. 19, 12 de febrero de 1846, p. 1. 
la opinión mediante el debate. ${ }^{72}$ Ramírez sospechaba ese cambio y creía que la derrota política de los monarquistas requería enfrentarlos en el debate público. En el terreno del prestigio literario, sin embargo, los liberales estaban en desventaja.

El Tiempo usaba ese prestigio de una manera sutil pero estratégica. La primera plana de cada número incluía una novela en entregas, empezando con La baronesa de Joux, de la autora romántica española y cubana Gertrudis de Avellaneda. La "parte indiferente" del periódico, generalmente en las últimas páginas, contenía poesías y ensayos sobre temas literarios "cuyo mérito fuera incuestionable", según los editores. Generalmente los autores eran españoles y muy conocidos, como José Zorrilla y Manuel Bretón de los Herreros, aunque también publicaron Amor clásico, del mexicano José María Esteva, fechado en Veracruz en $1846 .{ }^{73}$ Sólo dos poemas hacían referencia a México, ambos en elogio de la virgen de Guadalupe. ${ }^{74}$ Por lo demás, el "mérito incuestionable" en las poesías publicadas en El Tiempo consistía en evitar el patriotismo, los excesos románticos y la sátira.

Para contrarrestar esa aparente ventaja literaria, la sátira de Don Simplicio ofrecía una visión subversiva de las opiniones y los estilos considerados prestigiosos. En "La representación nacional”, Ramírez criticaba la abundancia de oradores vacíos ("Solones") que mentían a la muchedumbre. ${ }^{75}$ En "El Espectador y Don Simplicio", Ramírez afirmaba que los vacuos debates ideológicos entre periódicos eran inútiles porque como "los escritores públicos [...] su influjo ha sido nulo”. El argumento contenía una autocrítica. A El Espectador, que lo acusa de insultos, le contestaba: "no temas

${ }^{72}$ Palti, La política del disenso..., p. 46. Véase también a Elías J. Palti, La invención de una legitimidad..., Carlos Illades, Las otras ideas. Estudio sobre el primer socialismo en México, 18501935, México, Era/Universidad Autónoma Metropolitana-Cuajimalpa, 2008; Illades, Nación, sociedad y utopía...; Víctor Alberto Villavicencio Navarro, El camino del monarquismo mexicano decimonónico: momentos, proyectos y personajes, tesis de doctorado en Historia, México, Universidad Nacional Autónoma de México, esp. cap. 2.

${ }^{73}$ José María Esteva, “Amor clásico”, El Tiempo, t. 1, n. 57, 22 de marzo de 1846, p. 3. Esteva publicaría poemas patrióticos después de la invasión norteamericana. Vicente Quirarte, “Tiempo de canallas, héroes y artistas. El imaginario de la guerra entre México y Estados Unidos”, en Laura Herrera Serna (ed.), México en guerra, 1846-1848: perspectivas regionales, México, Consejo Nacional para la Cultura y las Artes, Museo Nacional de las Intervenciones, 1997.

${ }^{74}$ Un Quidam, "Poesía”, y M. de C. y Ch., "A unos lindos ojos negros”, El Tiempo, t. 1, n. 35, 28 de febrero de 1846, p. 4.

75 Nigromante, “La representación nacional”, c. 1846-1847, Don Simplicio, t. 1, n. 1, diciembre de 1845 , p. 6. 
esa infamia, pues que si a ti no te leen los mismos que te han asalariado, yo me leo solo y esto quedará entre nosotros". ${ }^{76} \mathrm{El}$ "espíritu público", decía en "Exorcismos del Nigromante", es un "laberinto de opiniones", y la prensa no es más que una engañosa mezcla de autores irrelevantes y públicos desinteresados. Ante los insultos de sus adversarios, el Nigromante ya no iba a repetir, para defenderse,

lo que han dicho doscientos autorcillos

y que parece nuevo a cada oyente

porque no lee ninguno. ${ }^{77}$

Más que la censura, el peligro para la libertad de expresión era la irrelevancia a la que la condenaba el elitismo de los letrados.

Este elitismo tenía bases literarias a las que era necesario enfrentar en su propio terreno. Para ello, la mejor herramienta era la sátira, porque servía de vehículo para dar voz y mofarse de los adversarios, es decir, porque era un género dialógico. La sátira servía también para reclamar un lugar específico en la división aparente entre movimientos estéticos, porque implicaba una apropiación selectiva de la tradición clásica y una crítica a la noción heroica del poeta romántico. La opción por este género significaba bajar a la poesía del pedestal de la belleza, y reconocer que la realidad nacional no necesitaba mucho artificio para dar risa. En una carta a Prieto en 1865 Ramírez todavía se preguntaba: “¿De qué sirve la comedia?”. Su respuesta era una crítica a la comedia francesa clásica, a la que consideraba incapaz de usar el "lenguaje de acción". Es pueril, agregaba Ramírez, burlarse de los avaros en comedias como las de Molière "cuando en los puestos públicos [...] pululan cornudos, codiciosos, embusteros, traidores y asesinos que el pueblo hoy en día puede juzgar muy bien" ${ }^{78}$

${ }^{76}$ El Nigromante, “El Espectador y Don Simplicio", Don Simplicio, t. 2, n. 15, 18 de febrero de 1846, p. 4. El texto de El Espectador disponible en línea a través de Readex no contiene referencias a Ramírez o Don Simplicio.

${ }^{77}$ Ramírez, "Exorcismos del Nigromante”, Don Simplicio, t. 2, n. 4, 10 de enero de 1846, p. 2.

78 "La verdadera comedia, la que tiene un porvenir seguro, es la que floreció cultivada por Aristófanes; lo demás no corresponde a las necesidades de la democracia; la comedia clásica debió extinguirse con los conventos." Nigromante, "[Carta segunda] a Fidel [Guillermo Prieto]”, Ures, marzo de 1865, en Ramírez, La palabra de la Reforma en la república de las letras..., p. 309-311. 
Al mismo tiempo, la sátira socavaba la idea de que los poetas eran seres más elevados que el común del pueblo. En una carta al Nigromante publicada en Don Simplicio, "el Diablo" se preciaba de sus "ribetes de poeta", sólo porque podía escribir un par de endecasílabos. ${ }^{79} \mathrm{En}$ "Un pueblo de máquinas”, Ramírez señalaba la hipocresía de los representantes nacionales que se creían escritores y héroes:

En la universidad, fiero soldado: en los cuarteles habla de poesía y leyes no ha estudiado. ${ }^{80}$

Ramírez desarrolló esta burla del elitismo libresco de manera más sistemática en un artículo titulado "La opinión pública". En él argumentaba que el problema con la opinión pública era la vaguedad del concepto mismo: ¿De quién era esa opinión: de naciones enteras o de un "pueblo muy mezquino"? ¿Cuál era su objeto: la política o "la crónica escandalosa de Iztacalco" (es decir, un pueblo pequeño y atrasado)? El texto señalaba la complicada relación entre opiniones individuales y colectivas: el Nigromante, decía, dará su "opinión privada" sobre "la opinión pública", "dejando a cada uno en particular que opine sobre la misma opinión y sobre el gobierno, como se le antoje". ${ }^{81}$ Suena a chiste, pero en ese momento de desencuentros ideológicos no parecía haber otra manera de resolver el problema de representar la razón colectiva desde la razón individual. En otras palabras, la idea del tribunal de la opinión, que definía la función de la opinión pública desde la primera mitad del siglo xix, no valía mucho para Ramírez. A través de la sátira de Don Simplicio, el objeto de la denuncia y el ridículo eran aquellos que se proclamaban voceros de la opinión pública, incluyendo los redactores del periódico. ¿Quién podía juzgar si los mismos jueces daban risa?

No se trataba, sin embargo, de una apelación a la vulgaridad. Los recursos humorísticos, la versificación, la caricatura y el sarcasmo de los poemas que aparecían en Don Simplicio no eran trucos para bajar el nivel de la discusión política, sino recursos para expandir el público y elevar la discusión periodística al nivel de la inteligencia común, llegando así a la "verdad

${ }^{79}$ Nigromante, "Cartas del diablo al Nigromante”, Don Simplicio, t. 3, n. 16, 22 de agosto de 1846, p. 2.

80 “Un pueblo de máquinas”, Don Simplicio, t. 2, n. 3, 28 de enero de 1846, p. 2.

${ }^{81}$ Nigromante, “La opinión pública”, Don Simplicio, t. 2, n. 32, 18 de abril de 1846, p. 1-2. 
deliberada”. La crítica ha señalado que la obra poética de Ramírez, si bien menos voluminosa que la de Prieto, nunca dejó de caracterizarse por su consistencia y corrección. Ramírez preservaba, aunque fuera tácitamente, la premisa ilustrada de que la razón individual era también universal. En "La soberanía de la inteligencia" ésta era la base de una profesión de fe republicana citada anteriormente:

Para cada cosa hay ciencia;

y con escasa medida

a cada hombre repartida

ha sido la inteligencia. ${ }^{82}$

Ramírez proponía una poesía satírica que no buscara la perfección ni la gloria pero que sirviera de instrumento para hacer "oír la voz de la libertad y de la ilustración a los pueblos”. El precio de usar así a la poesía era la pérdida del prestigio literario y la seguridad personal, dos bienes que ya entonces comenzaban a verse como derechos de los intelectuales. Careciendo de aspiraciones literarias para "mis inocentes sátiras”, Ramírez aceptaba los riesgos de escribir en esa clave. ${ }^{83}$ En un ensayo sin firma de 1846, "Variedades. Estudios literarios de Don Simplicio", los redactores del periódico admitían que era necesaria la sátira para hacer reaccionar al gobierno y a los lectores, aunque esto no siempre sucediera de la manera esperada: "Esto de escribir satírico es peliagudo, y hacerse el gracioso suele tener el leve defecto de no caer en gracia". ${ }^{84} \mathrm{El}$ desprecio a los atributos literarios exponía a los autores a los peligros de la interpretación. La sátira utilizaba una mentira (nombres falsos, referencias veladas, situaciones imposibles pero alusivas) para decir una verdad que los lectores podían decodificar fácilmente si estaban al tanto de la actualidad. Pero, por esa misma razón, la autoridad podía interpretarla como un texto subversivo, y los críticos como un arte menor. ${ }^{85}$

${ }^{82}$ Nigromante, "La soberanía de la inteligencia. Al Tiempo", Don Simplicio, t. 2, n. 19, 4 de marzo de 1846, p. 3.

${ }^{83}$ Nigromante, "Justificación del Nigromante", Don Simplicio, t. 2, n. 16, 21 de febrero de 1846 , p. 3.

${ }^{84}$ EE, "Variedades. Estudios literarios de Don Simplicio", Don Simplicio, t. 2, n. 24, 21 de marzo de 1846, p. 1-3. El texto en prosa empieza como carta al lector y continúa como conversación entre Nigromante, Don Simplicio y Cantárida.

${ }^{85}$ Fuertes-Arboix, La sátira política en “Fray Gerundio”..., p. 158, 160. 
Poetas en bancarrota

No es tan sorprendente, entonces, que Ramírez se pusiera a teorizar sobre la poesía en medio de la crisis nacional. Se trataba, en primer lugar, de un trabajo necesario en ese momento en el que la política, plagada de ignorancia e hipocresía, parecía desasociarse de la subjetividad. En consonancia con su persona pública, provocadora y autocrítica, los versos de Ramírez en Don Simplicio eran una confesión de su propia ineptitud para estar a la altura de las circunstancias. Escribiendo sobre sí mismo, negaba ser un poeta visionario: "con mis inocentes sátiras no aspiro yo a colocar un laurel sobre mis sienes" ${ }^{86}$ Apenas creía tener lectores, como vimos arriba.

Ramírez no se definía como un poeta, y ciertamente no creía que el poeta fuera una especie de profeta de una verdad que trascendía la política. En ello se distinguía de otros liberales, como Francisco Zarco quien en 1852 listaba los atributos de "el poeta" como una mezcla de superioridad y marginalidad, deseo y sufrimiento. La dignidad política del poeta, según Zarco, se encontraba en tensión con su búsqueda de la belleza y los placeres. ${ }^{87}$ Por el contrario, Ramírez mostraba muy poco respeto a los poetas como personajes públicos. Señalaba el riesgo de que se volvieran voceros de un patriotismo artificial y fácilmente controlado desde el poder. En un artículo contra la centralización política advertía que si una ciudad dominara todo un país "los poetas cantarán los héroes, mientras los pueblos los maldigan". ${ }^{8}$ Prieto, en sus Memorias de mis tiempos, recordaba que en esos años hasta Santa Anna tenía su "coplero”, Ignacio Sierra y Rosso, que le escribía versos llenos de alabanzas a cambio de puestos públicos. ${ }^{89}$

Esta poesía bastardeada era un efecto del creciente número de autores que aparecían en una esfera pública tan dispersa que la crítica parecía imposible. Como otros autores de su momento, Ramírez creía que la poesía se había vulgarizado y que había demasiados poetas de mala calidad. El problema,

${ }^{86}$ Nigromante, “Justificación del Nigromante”, Don Simplicio, t. 2, n. 16, 21 de febrero de 1846 , p. 3.

87 "El poeta" [1852], en Francisco Zarco, Obras completas de Francisco Zarco. XVII. Literatura y variedades, poesía, crítica literaria, ed. de Boris Rosen Jelómer, México, Centro de Investigación Científica Ing. Jorge L. Tamayo, 1994, p. 824-833. Sobre el romanticismo inglés, véase Eagleton, How to Read a Poem, p. 12.

88 "Sobre la influencia de la extensión territorial en la ignorancia y miseria de las naciones”, Don Simplicio, t. 2, n. 17, 25 de febrero de 1846, p. 4.

89 Prieto, Obras completas, p. 384. 
en otras palabras, no era con los lectores sino con los autores. Según Ramírez, en el pasado la alta inspiración residía en las academias, pero "no así ahora, cuando los cantos de las musas resuenan en las cátedras y en las oficinas, en las plazas y en las calles: todo el mundo sabe fumar y hacer versos". La poesía ya ni siquiera puede justificarse a sí misma mediante la crítica, según Ramírez, "pues la gloria del poeta no pasa de una academia, y hay cien academias en cada pueblo, que se desprecian mutuamente". ${ }^{90}$ Un ensayo anónimo de la Revista Científica y Literaria de México de 1845, en la que Ramírez colaboraba, denunciaba a los poetas actuales que plagiaban, publicaban demasiado, sobre todo en los periódicos, y recitaban sus poemas a la menor oportunidad.91 Esta crítica se expresaba mediante la contraposición entre el verdadero poeta y la figura despreciable del versificador. Para éste, según Zarco, "Poesía es el arte de hacer versos de todos tamaños, sobre toda clase de asuntos; por ejemplo, sobre el modo de encender un cerillo, y sobre lo que se necesita para poder nadar". 92

La respuesta de Ramírez no era simplemente el desprecio sino también la teoría. En febrero de 1846, Ramírez publicó un ensayo sobre la poesía titulado "Justificación del Nigromante". Se preguntaba de entrada de qué servía la poesía: "cuál puede ser la utilidad de un arte tan trabajoso para muchos que se hacen memorables con sus obras, y para otros que lo cultivan, como fugaz diversión". La respuesta no se hallaba en ninguna capacidad oculta de la poesía para dar "a las ideas expresiones que les niega la miseria del lenguaje”. Esta capacidad era una tesis favorita del romanticismo, que veía en la poesía un eco de la interioridad del hombre que no podía ser expresada de otra forma, un don divino. Para Ramírez, el lenguaje contenía suficientes palabras para nombrarlo todo, incluso las pasiones, que al fin y al cabo eran heredadas. El poeta no justificaba la poesía. Tampoco servía la poesía para embellecer el contenido de las ideas porque "el número de las alhajas de que puede disponer el ingenio está agotado”. Según Ramírez: “en la práctica, doloroso es decirlo, la poesía ha hecho bancarrota”. Ni siquiera la épica podía justificar la poesía actual: si las "naciones semibárbaras" habían

${ }^{90}$ Nigromante, "Justificación del Nigromante”, Don Simplicio, t. 2, n. 16, 21 de febrero de 1846 , p. 3.

${ }^{91}$ Una sátira de los malos poetas plagiarios en PC, "Poesía romántica. Entriagos y vestiglos. A los plagiarios de Zorrilla”, en Revista Científica y Literaria de Méjico publicada por los antiguos redactores del Museo Mejicano, Imp. Lito. Calle de la Palma 4, 1845, p. 325-327.

${ }^{92}$ Francisco Zarco, "Arte poética” [1851], La Ilustración Mexicana, t. I, p. 241-245, reproducido en Zarco, Obras completas de Francisco Zarco..., p. 778-787. 
podido contar las epopeyas de sus héroes, un canto homérico sobre la revolución francesa hoy "sería silbado". ${ }^{93}$

"Mis estudios clásicos", un poema de 112 versos endecasílabos de junio de 1846, continuaba la reflexión de la "Justificación del Nigromante". La épica era imposible en las condiciones actuales porque si cada nación necesitaba una poesía diferente también

hay mucho de locura en la poesía;

que cada edad, cada nación padece

diferente locura.

Los mexicanos, decía Ramírez, no deliraban con el Olimpo, según Ramírez, y su Troya fue la derrota de San Jacinto, es decir, una pobre imitación del original; tampoco eran guerreros, sino que vivían para los placeres. Concluía el poema dudando de la utilidad de ese trabajo de anticuario que era leer y reproducir a los clásicos: "ipor qué con torpe afán en los archivos / buscar marchitas rosas". La "bancarrota" de la poesía implicaba una condena al clasicismo y a la búsqueda de la perfección. El autor reconocía, en "Mis estudios clásicos", que "mis versos me gustan" aunque no fueran inspirados por la musa. Un "doctor” le había recomendado leer a griegos y latinos pero él lo hacía lentamente, se distraía, necesitaba el diccionario, y la Eneida "me va a costar más tiempo y más trabajo / que aprender un oficio o cualquier ciencia". ${ }^{94}$ Los sentimientos amorosos en general ya no ameritaban el intento, pues "sería una locura consumirse en el trabajo por hacer una elegía a una coqueta que mañana se olvidará; una oda que tendrá la vida de un periódico político". ${ }^{95}$ En el registro irónico y autocrítico de Don Simplicio, "Mis estudios clásicos" contenía una trampa que sólo el lector cercano podía detectar. "El Nigromante" (es decir, el yo autoral satírico, provocador y heterodoxo) no era lo mismo que "Ignacio Ramírez" (el escritor real, autodidacto y combativo). Ramírez conocía muy bien los modelos

${ }^{93}$ En esto coincide con el esquema evolucionario de los géneros poéticos de Hugo, Oeuvres complètes de Victor Hugo. Volume 37. Cromwell, Paris, Hetzel-Quantin, 1881, p. 5. El ensayo en Nigromante, "Justificación del Nigromante", Don Simplicio, t. 2, n. 16, 21 de febrero de 1846 , p. 3.

${ }^{94}$ Nigromante, "Mis estudios clásicos”, Don Simplicio, t. 3, n. 1, n. 4, 11 de julio de 1846, p. 2-3.

${ }^{95}$ Nigromante, “Justificación del Nigromante”, Don Simplicio, t. 2, n. 16, 21 de febrero de 1846 , p. 3. 
clásicos y frecuentemente los citaba o traducía. Su poesía posterior muestra su capacidad para usar diversas formas poéticas y su admiración por poetas, como fray Luis de León, que encontraron el mejor modo para cantarle a su "nación encadenada". 96

Ramírez, en otras palabras, reivindicaba en 1846 el derecho a no leer, o por lo menos a no leer una tradición europea cargada de un nefasto peso político. En "Justificación del Nigromante" afirmaba que las influencias literarias europeas tampoco eran una razón para el esfuerzo que requería la poesía. Los poetas famosos de tiempos recientes "hablaban a naciones envejecidas, y sin más que traducir a los antiguos, porque los descendientes de los latinos y de los griegos heredaron todo, menos la poesía de sus padres".

Es paradójico ver a un escritor condenar a la inutilidad a un género al que, al mismo tiempo, comenzaba a dedicarle muchas horas. Pero, como en otros escritos de Ramírez, hay un giro sorpresivo al final de "Justificación del Nigromante”. Tras preguntarse nuevamente "¿cuál es la misión de la poesía en el siglo en que vivimos?" su respuesta es simple: "La de instrumento". Se deben hacer versos para agradar "a mi querida" o para conseguir trabajo en el gobierno o para tener "algunos pesos en el bolsillo", pero también para hacer "oír la voz de la libertad y de la ilustración a los pueblos espantados por la severidad de la ciencia”. Por eso el Nigromante no quiere, como poeta, "un laurel sobre mi sien" sino, como periodista de combate, "un cordel" para "el cuello de esos hipócritas" que son sus adversarios políticos. ${ }^{97}$

En la poética materialista y escéptica de Ramírez, la clave de la utilidad de la poesía estaba en su capacidad para dar placer. El mayor gozo que ofrecía el verso era la demostración reiterada de que la inteligencia era democrática y enemiga de las pretensiones intelectuales y oficiales. La poesía daba placer a "la muchedumbre" porque la inteligencia pertenecía a todos, no sólo a los académicos y los gobernantes. La satisfacción de la risa era una recompensa en sí misma, aunque fuera dirigida a uno mismo o al propio país. En muchos de los textos en prosa en Don Simplicio encontramos versos intercalados que ejemplificaban el punto a discusión de una manera breve, como un pequeño regalo de humor. En el artículo "Transacción”, por ejemplo, Ramírez le espetaba, en verso, a los empleados corruptos de los juzgados:

${ }^{96}$ Nigromante, “A Ezequiel Montes (Enviándole un libro de fray Luis de León)” [1876], en Ramírez, La palabra de la Reforma en la república de las letras..., p. 395.

${ }^{97}$ Nigromante, "Justificación del Nigromante", Don Simplicio, t. 2, n. 16, 21 de febrero de 1846 , p. 3. 
Jamás un código empuñas

y en ninguno hay, ¡oh escribano!

Tus fórmulas, ¿cómo, hermano,

tú las tienes en las uñas?98

Estos pequeños obsequios no son decorativos, sino que nos dan la clave de la imbricación del proyecto literario con el político. Ramírez afirmaba que la búsqueda del placer era el principio de la vida política: el secreto para la estabilidad de cualquier gobierno es su capacidad para satisfacer los deseos de la muchedumbre. En el ensayo "A los viejos", publicado en el primer número de Don Simplicio, Ramírez afirmaba que en México esos deseos consistían en "saborear una botella, pasear en coche y disfrutar de una hermosa. [...] Y éstos son los tres principios de toda verdadera Constitución republicana”. La conclusión aparecía en dos endecasílabos integrados en la prosa: "Muchedumbre: midamos la bondad de los gobiernos, por los placeres que nos proporcionen”. Ramírez le quitaba lo sagrado a la soberanía conectando la efectividad del Estado con el gozo masculino de la vida cotidiana. ${ }^{99}$

El vínculo entre placer, lenguaje y poesía, que en Don Simplicio era implícito, adquirirían una forma teórica en las lecciones de literatura que Ramírez publicó primero en El Renacimiento, la revista editada por Altamirano a partir de 1869. Muchas de estas ideas ya estaban presentes en las clases de "Bella Literatura" que Ramírez dio en el Instituto Literario de Toluca en 1851, y que luego usaría para sus clases en la Escuela Preparatoria de la capital. ${ }^{100}$ Una versión de las lecciones publicada en 1884 empieza examinando el lenguaje como "una manifestación fisiológica de la organización humana", la base del "lenguaje de acción”. El placer, de esta manera, se conecta con la inteligencia en el marco de la interacción social. Los tropos de la literatura eran, según Ramírez, maneras de extender la significación de las palabras. La versificación le daba una dimensión musical al lenguaje. La "belleza literaria" residía "en los objetos representados por las ideas, en el instrumento literario que es el lenguaje, y por último, en la utilidad de las mismas producciones literarias”. Más que un atributo in-

${ }^{98}$ Nigromante, “Transacción”, Don Simplicio, t. 2, n. 28, 4 de abril de 1846, p. 3.

${ }^{99}$ El Nigromante, “A los viejos”, Don Simplicio, t. 1, n. 1, diciembre de 1845, p. 2.

${ }^{100}$ El placer en relación con las bases fisiológicas y sociales del lenguaje analizado en RayAlexander, Blood, Sweat, and Tears..., p. 267 y s. Sin embargo, el autor afirma que la capacidad de la literatura para comunicar emoción es más importante en Ramírez que su función racional, p. 277. Se trata de un falso dilema derivado de una lectura romántica. 
trínseco, la belleza era una condición dialógica que hacía posible la fusión de política y poética en Ramírez: "la belleza literaria escoge de preferencia entre los fenómenos de la naturaleza aquellos á quienes puede dar un carácter social: lenguaje y sociedad son dos encarnaciones de una misma propensión en el hombre: quien dice orador y poeta dice público". ${ }^{101}$

Como lo adelantaban de una manera concreta los escritos de Don Simplicio, el sitio clave para juzgar la literatura y su función social no era el poeta en sí, sino la relación entre éste y su audiencia. En las lecciones, Ramírez proponía el estudio de la recepción de la literatura como vía para entender históricamente al lenguaje:

El vulgo debe admirar a los poetas y a los oradores; y el literato debe buscar en ellos las causas que producen su admiración, y entonces descubrirá los secretos que el ingenio emplea para infundir en los pensamientos comunes de la especie humana, germen inevitable de las obras maestras, una alma con su vigorosa agitación, y una vida con la hermosura brillante de una juventud eterna. ${ }^{102}$

La clave del éxito de la literatura como lenguaje de acción era ofrecer el placer y la utilidad mediadas socialmente en el espacio público.

Junto con Prieto, Ramírez adoptó desde la época de Don Simplicio un proyecto que iría más allá de la belleza literaria como vehículo del nacionalismo y propondría que el lenguaje mismo debía cambiar para ser de utilidad política. Prieto se encargaría de incorporar sistemáticamente el habla popular en una obra en verso extensísima y en su mayor parte al servicio de la causa política liberal. Ramírez buscaría una conexión más profunda que podemos ver mejor en su obra en prosa y su interés por la filología y los lenguajes antiguos de México. ${ }^{103}$ En las lecciones de literatura no habla de la sátira, y es poca la que se encuentra en su obra posterior a Don Simplicio. Esto ha llevado a los estudiosos a asumir que una concepción de la belleza tradicional se

${ }^{101}$ Ignacio Ramírez, Lecciones de literatura, México, Imp. de F. Díaz de León, 1884, p. 105.

${ }^{102}$ Ignacio Ramírez, "Dos lecciones inéditas sobre literatura dadas en el Instituto Polígloto de Toluca” [1855], Ramírez, Obras de Ignacio Ramírez, v. I, p. 299. Su interés por lenguajes prehispánicos continuaría en las décadas siguientes.

${ }^{103}$ Ignacio Ramírez, "Discursos y trabajos literarios sobre la Historia Antigua de México", Revista Científica y Literaria de Méjico publicada por los antiguos redactores del Museo Mejicano, México, Imp. Calle de la Palma, 1845, p. 21-22; Ignacio Ramírez, "Revisión de obras. Diccionario de sinónimos de la lengua castellana, por don José Gómez de la Cortina”, Revista Científica y Literaria de Méjico publicada por los antiguos redactores del Museo Mejicano, México, Imp. Calle de la Palma 4, 1845, p. 76-77. 
encuentra detrás de la función estética del placer que proponía Ramírez. ${ }^{104}$ La explicación puede ser más simple. Después de la guerra contra Estados Unidos, el tono y la forma de la poesía socialmente efectiva debían cambiar, y la risa ya no sonaba bien. ${ }^{105}$ Según Vicente Quirarte, la derrota del 47 originó "una literatura de urgencia" que expresaba dolor o indignación, o usaba la sátira con lenguaje popular como consuelo o como arma de combate. ${ }^{106}$ En abril de 1847, los redactores de Don Simplicio se preguntaban “¿cómo apelar á la lira de Quevedo cuando el corazón llora sangre por nuestras desgracias nacionales?" 107 Ramírez participó en algunos combates durante la invasión y, desde una posición privilegiada como oficial, probablemente experimentó la misma triste admiración que Prieto reportó en sus memorias al ver morir a muchos de sus coetáneos en la guerra contra los invasores. ${ }^{108}$ La guerra también significó una rápida maduración personal. En 1847 fue a Toluca, donde ocupó puestos de importancia en el gobierno de Francisco Modesto de Olaguíbel en el Estado de México, incluyendo la dirección del Instituto Científico y Literario. Ese mismo año se casó con Soledad Mateos, con quien tendría cinco hijos. Según sus descendientes, Ramírez decía que 1847 había sido el año más feliz de su vida. ${ }^{109} \mathrm{Tal}$ vez haya sido el año más triste para México, pero la anécdota sugiere la valla entre lo privado y lo público que Ramírez comenzaba entonces a construir. La poesía que escribió desde entonces no fue abundante ni se publicó en un volumen durante su vida. El cambio de tono posterior a la guerra quedó registrado en su celebrado poema de 1859, "Después de los asesinatos de Tacubaya”, en sus composiciones nostálgicas y filosóficas para la Sociedad Gregoriana, y en algunos poemas de amor de su vejez.

Ramírez, podríamos decir, simplemente siguió avanzando después de proponer una crítica radical sobre la función de la literatura en la vida pública. Otros retomaron la idea. La literatura nacional, gracias en buena

${ }^{104}$ Martínez Carrizales, "Ignacio Ramírez, teórico de la literatura”, p. 447. Citado en RayAlexander, Blood, Sweat, and Tears..., p. 481.

${ }^{105}$ Malcom D. McLean, Vida y obra de Guillermo Prieto, México, El Colegio de México, 1960, p. 27. Prieto volvería a ocupar la sátira durante la guerra de tres años y la intervención francesa. McLean, Vida y obra de Guillermo Prieto, p. 33. Sobre las posibilidades de una historia de la risa Mikhail Mikhailovich Bakhtin, La cultura popular en la Edad Media y en el Renacimiento: el contexto de François Rebelais, 2a. reimp., México, Alianza, 1993.

${ }^{106}$ Quirarte, “Tiempo de canallas, héroes y artistas...”, p. 79, 83.

107 Citado por Sánchez Archundia, Desde la Asnópolis..., p. 45.

108 Prieto, Obras completas, v. 1, p. 401.

109 Arellano, Ignacio Ramírez, El Nigromante..., p. 48. 
medida su trabajo como educador, comenzó a establecerse a partir de una absorción más sistemática de los ejemplos clásicos y contemporáneos. Su alumno Altamirano es un ejemplo de esa nueva erudición, y uno de los artífices, junto con Zarco, de un proyecto nacional de reconstrucción cultural durante la República Restaurada en la que la literatura tendría una función "útil al Estado". ${ }^{110}$ Ramírez era demasiado escéptico como para adoptar plenamente esa estética nacionalista.

La idea de que la poesía era un vehículo central para la reconstrucción nacional o el robustecimiento de una esfera pública crítica y abierta perdió vigencia en las últimas décadas del siglo. Entre los cuarenta y el triunfo liberal de los sesenta, el encono ideológico y las guerras no hicieron más que profundizar la irrelevancia del periodismo que Ramírez señalaba en su debate con El Espectador ("a ti no te leen los mismos que te han asalariado, yo me leo solo"). Aunque la inteligencia estaba bien repartida, los gobiernos ya no sólo blandían "espadas de papel”. En ese marco cronológico más amplio, Don Simplicio, ese periódico tan precario como el país en el que aparecía, fue una aventura pasajera, una de esas formas de la locura que era la poesía. Le costó la cárcel a Ramírez, pero a cambio le permitió fundar una teoría sobre la poesía como ejercicio de la crítica. En "La resurrección de Don Simplicio" Ramírez sintetizaba de manera nigromántica la aventura de 1846 y prefiguraba los tiempos oscuros que vendrían:

Queriendo hallar Don Simplicio

las leyes de la razón

y darlas a la nación,

estudiando, perdió el juicio.

Y no obstante el desconcierto

de sus ideas y acciones,

hubo riñas y prisiones,

y de susto cayó muerto. ${ }^{111}$

${ }^{110}$ Ignacio Ramírez, "Discurso sobre el objeto de la literatura", en el Liceo Hidalgo, 1 de junio de 1851, Zarco, Obras completas de Francisco Zarco, p. 764-777.

111 "La resurrección de don Simplicio", Don Simplicio, t. 3, n. 2, 4 de julio de 1846, p. 2. 


\section{Bibliografía}

Aguilar, Luis Miguel, La democracia de los muertos, México, Cal y Arena, 1988. Altamirano, Ignacio Manuel, Obras completas. XiII. Escritos de literatura y arte, tomo 2, ed. de José Luis Martínez, México, Secretaría de Educación Pública, 2011.

Arellano, Emilio, Ignacio Ramírez, El Nigromante. Memorias prohibidas, México, Planeta, 2009.

BAKHtin, Mikhail Mikhailovich, La cultura popular en la Edad Media y en el Renacimiento: el contexto de François Rebelais, 2a. reimp., México, Alianza, 1993.

Blanco, José Joaquín, “Destellos de El Nigromante. Retratos con paisaje”, Nexos: Sociedad, Ciencia, Literatura, v. 27, n. 326, febrero de 2005. Disponible en https:// www.nexos.com.mx/?p=11413.

Buffington, Robert M., A Sentimental Education for the Working Man: The Mexico City Penny Press, 1900-1910, Durham (North Carolina), Duke University Press, 2015.

Bustamante, Carlos María de, Diario histórico de México, 1822-1848: del licenciado Carlos María Bustamante, 1a. edición electrónica, edición de Josefina Zoraida Vázquez Vera y Héctor Cuauhtémoc Hernández Silva, México, El Colegio de México/Centro de Investigación y Estudios Superiores en Antropología Social, 2001.

Castro, Miguel Ángel, “Ignacio Ramírez, lecturas pendientes”, en Ignacio Ramírez, La palabra de la Reforma en la república de las letras: una antología general, México, Universidad Nacional Autónoma de México, 2009, p. 413-435.

Domínguez Michael, Christopher, La innovación retrógrada. Literatura mexicana, 1805-1863, México, El Colegio de México, 2016.

Eagleton, Terry, How to Read a Poem, Malden (Massachussets), Blackwell, 2007.

Fowler, Will (ed.), Forceful Negotiations: The Origins of the Pronunciamiento in Nineteenth-Century Mexico, Lincoln, University of Nebraska Press, 2010.

Fuente, Ariel de la, "Los comentaristas del Facundo y sus prejuicios: Respuesta a Adriana Amante y a Elías Palti”, Boletín del Instituto de Historia Argentina y Americana "Dr. Emilio Ravignani”, n. 44, 2016, p. 201-222.

Fuertes-Arboix, Mónica, La sátira política en "Fray Gerundio” (1837-1842) de Modesto Lafuente, tesis de doctorado, The Ohio State University, 2006.

Granados, Luis Fernando, Sueñan las piedras. Alzamiento ocurrido en la ciudad de México, 14, 15 y 16 de septiembre de 1847, México, Consejo Nacional para la Cultura y las Artes, 2003.

Gutiérrez Nájera, Manuel, Obras, ed. de José Luis Martínez, México, Fondo de Cultura Económica, 2003. 
Hale, Charles A., Mexican Liberalism in the Age of Mora, New Haven, Yale University Press, 1968.

Hugo, Victor, Oeuvres complètes de Victor Hugo, Paris, Hetzel-Quantin, 1880.

, Oeuvres complètes de Victor Hugo. Volume 37. Cromwell, Paris, Hetzel-Quantin, 1881.

Illades, Carlos, Nación, sociedad y utopía en el romanticismo mexicano, México, Consejo Nacional para la Cultura y las Artes, 2005.

Las otras ideas. Estudio sobre el primer socialismo en México, 1850-1935, México, Era/Universidad Autónoma Metropolitana-Cuajimalpa, 2008.

IngWersen, Lance R., Mexico City in the Age of Theater, 1830-1901, tesis de doctorado, Universidad de Vanderbilt, 2017.

Jones, Steven E., "Nineteenth-Century Satiric Poetry”, en Rubén Quintero (ed.), A Companion to Satire: Ancient and Modern, Maiden (Massachussets), Blackwell Publishing, 2007.

Kurz, Andreas, "Ignacio Ramírez o El amor/odio romántico a la autoridad”, Estudios: Filosofía, Historia, Letras, v. XII, n. 108, primavera de 2014, p. 137-152.

Lamartine, Alfonso de, "Sobre los destinos de la poesía”, en Eulalio María Ortega (ed.), El año nuevo de 1840. Tomo IV. Edición facsimilar, México, Universidad Nacional Autónoma de México, 1994, p. 203-233.

Maciel, David, “Don Simplicio y El 'Nigromante' ”, Relaciones, v. 2, n. 8, 1981, p. 115-131.

, Ignacio Ramírez, ideólogo del liberalismo social en México, México, Universidad Nacional Autónoma de México, 1980.

Martínez CARrizales, Leonardo, “Ignacio Ramírez, teórico de la literatura”, en Ignacio Ramírez, La palabra de la Reforma en la república de las letras. Una antología general, México, Universidad Nacional Autónoma de México, 2009, p. 437-448.

McLean, Malcom D., Vida y obra de Guillermo Prieto, México, El Colegio de México, 1960.

Monsiváis, Carlos, "La expresión radical de Ignacio Ramírez”, en David R. Maciel (ed.), Obras completas de Ignacio Ramírez "El Nigromante”, México, Centro de Investigación Científica Jorge L. Tamayo, 1984, v. 3, p. V-XXX.

Nash, Suzanne, Les Contemplations of Victor Hugo: An Allegory of the Creative Process, Princeton, Princeton University Press, 1976.

Ousselin, Edward, “Victor Hugo's European Utopia”, Nineteenth-Century French Studies, v. 34, n. 1/2, 2005, p. 32-43.

PAlti, Elías J., La política del disenso. La "polémica en torno al monarquismo" (México, 1848-1850)... y las aporías del liberalismo, México, Fondo de Cultura Económica, 1998. 
La invención de una legitimidad. Razón y retórica en el pensamiento mexicano del siglo XIX (Un estudio sobre las formas del discurso político), México, Fondo de Cultura Económica, 2005.

PAnI, Erika J., "Intervention and Empire: Politics as Usual?", en Will Fowler (ed.), Malcontents, Rebels, and Pronunciados: The Politics of Insurrection in NineteenthCentury Mexico, Lincoln, University of Nebraska Press, 2012, p. 236-254.

Piccato, Pablo, La tiranía de la opinión. El honor en la construcción de la esfera pública en México, traducción de Lucía Rayas, México, El Colegio de Michoacán/ Instituto de Investigaciones Dr. José María Luis Mora, 2015.

Prieto, Guillermo, Obras completas XI. Poesía satírica. Poesía religiosa, edición de Boris Rosen Jélomer, México, Consejo Nacional para la Cultura y las Artes, 1995. Obras completas. Volumen 1. Memorias de mis tiempos, edición de Boris Rosen Jelómer, México, Consejo Nacional para la Cultura y las Artes, 2005.

Prieto, Guillermo, et al., Apuntes para la historia de la guerra entre México y los Estados Unidos [edición facsimilar de la de 1848], México, Siglo XXI Editores, 1970. QuirarTE, Vicente, “Tiempo de canallas, héroes y artistas. El imaginario de la guerra entre México y Estados Unidos”, en Laura Herrera Serna (ed.), México en guerra, 1846-1848: perspectivas regionales, México, Consejo Nacional para la Cultura y las Artes, Museo Nacional de las Intervenciones, 1997, p. 55-91.

RAmA, Ángel, La crítica de la cultura en América Latina, selección y prólogos de Saúl Sosnowski y Tomás Eloy Martínez, Caracas, Biblioteca Ayacucho, 1985.

Ramírez, Ignacio, Lecciones de literatura, México, Imp. de F. Díaz de León, 1884. Obras de Ignacio Ramírez, edición de Ignacio Manuel Altamirano, México, Oficina Tip. de la Secretaría de Fomento, 1889.

La palabra de la Reforma en la república de las letras. Una antología general, México, Universidad Nacional Autónoma de México, 2009.

RayAlexAnder, Christopher Mark, Blood, Sweat, and Tears. Literary Creation and National Sentiment in 19th Century Mexico, tesis de doctorado, The Johns Hopkins University, 2016.

Reyes Heroles, Jesús, El liberalismo mexicano, México, Universidad Nacional Autónoma de México, 1957.

RojAs, Rafael, y José Antonio Aguilar, El republicanismo en Hispanoamérica. Ensayos de historia intelectual y política, México, Centro de Investigación y Docencia Económicas/Fondo de Cultura Económica, 2002.

RojAs, Rafael, La escritura de la independencia. El surgimiento de la opinión pública en México, México, Taurus/Centro de Investigación y Docencia Económicas, 2003. RosA, Luis de la, "Utilidad de la literatura en México”, en Jorge A. Ruedas de la Serna (coord.), La misión del escritor. Ensayos mexicanos del siglo XIX, México, Universidad Nacional Autónoma de México, 1996, p. 89-103. 
Rosen, Boris, y David R. Maciel (eds.), Obras completas de Ignacio Ramírez "El Nigromante”, México, Centro de Investigación Científica Ing. Jorge L. Tamayo, 1984.

Rousseau, Jean-Jacques, Du contrat social, ou principes du droit politique. Collection complète des oeuvres, Genève, 1780-1789, Paris, Le Pléiade, 1866. Disponible en http://www.rousseauonline.ch/Text/du-contrat-social-ou-principes-du-droitpolitique.php.

SÁnchez Archundia, Alejandra, Desde la Asnópolis. Narraciones de la nación "Desde Abajo": Don Simplicio (1845-1847), tesis de licenciatura en Historia, México, Universidad Nacional Autónoma de México, 2011.

Santoni, Pedro, Mexicans at Arms. Puro Federalists and the Politics of War, 18451848, Fort Worth, Texas Christian University Press, 1996.

Sierra, Justo, Juárez: su obra y su tiempo, México, Universidad Nacional Autónoma de México, 1984, v. 3.

SKIRIUS, John, "Pensamiento cultural y educativo de Ignacio Ramírez", en La palabra de la Reforma en la república de las letras. Una antología general, México, Universidad Nacional Autónoma de México, 2009, p. 449-459.

Soto Estrada, Miguel, La conspiración monárquica en México, 1845-1846, México, Offset, 1988.

Tola de Habich, Fernando, "Prólogo", en El año nuevo de 1837. Tomo I. Edición facsimilar, México, Universidad Nacional Autónoma de México, 1996, p. IV-CXLIII.

VÁzquez, Josefina Zoraida, "Search of Power: The Pronunciamientos of General Mariano Paredes y Arrillaga”, en Will Fowler (ed.), Malcontents, Rebels, and Pronunciados: The Politics of Insurrection in Nineteenth-Century Mexico, Lincoln, University of Nebraska Press, 2012, p. 171-204.

Villavicencio Navarro, Víctor Alberto, El camino del monarquismo mexicano decimonónico: momentos, proyectos y personajes, tesis de doctorado en Historia, México, Universidad Nacional Autónoma de México, 2015.

Webster Henestrosa, Cérida, Don Simplicio y el proyecto de nación liberal social, tesis de licenciatura en Historia, México, Universidad Nacional Autónoma de México, 2006.

Weinberg, Liliana, "La palabra de la Reforma en la república de las letras”, en Ignacio Ramírez. La palabra de la Reforma en la república de las letras. Una antología general, México, Fondo de Cultura Económica/Fundación para las Letras Mexicanas/Universidad Nacional Autónoma de México, 2009, p. 15-94.

Zarco, Francisco, Obras completas de Francisco Zarco. XVII. Literatura y variedades, poesía, crítica literaria, ed. de Boris Rosen Jelómer, México, Centro de Investigación Científica Ing. Jorge L. Tamayo, 1994. 